\title{
PIV Measurements of Supersonic Internally-Mixed Dual-Stream Jets
}

James E. Bridges and Mark P. Wernet

Glenn Research Center, Cleveland, Ohio 


\section{NASA STI Program . . . in Profile}

Since its founding, NASA has been dedicated to the advancement of aeronautics and space science. The NASA Scientific and Technical Information (STI) program plays a key part in helping NASA maintain this important role.

The NASA STI Program operates under the auspices of the Agency Chief Information Officer. It collects, organizes, provides for archiving, and disseminates NASA's STI. The NASA STI program provides access to the NASA Aeronautics and Space Database and its public interface, the NASA Technical Reports Server, thus providing one of the largest collections of aeronautical and space science STI in the world. Results are published in both non-NASA channels and by NASA in the NASA STI Report Series, which includes the following report types:

- TECHNICAL PUBLICATION. Reports of completed research or a major significant phase of research that present the results of NASA programs and include extensive data or theoretical analysis. Includes compilations of significant scientific and technical data and information deemed to be of continuing reference value. NASA counterpart of peer-reviewed formal professional papers but has less stringent limitations on manuscript length and extent of graphic presentations.

- TECHNICAL MEMORANDUM. Scientific and technical findings that are preliminary or of specialized interest, e.g., quick release reports, working papers, and bibliographies that contain minimal annotation. Does not contain extensive analysis.

- CONTRACTOR REPORT. Scientific and technical findings by NASA-sponsored contractors and grantees.
- CONFERENCE PUBLICATION. Collected papers from scientific and technical conferences, symposia, seminars, or other meetings sponsored or cosponsored by NASA.

- SPECIAL PUBLICATION. Scientific, technical, or historical information from NASA programs, projects, and missions, often concerned with subjects having substantial public interest.

- TECHNICAL TRANSLATION. Englishlanguage translations of foreign scientific and technical material pertinent to NASA's mission.

Specialized services also include creating custom thesauri, building customized databases, organizing and publishing research results.

For more information about the NASA STI program, see the following:

- Access the NASA STI program home page at http://www.sti.nasa.gov

- E-mail your question via the Internet to help@ sti.nasa.gov

- Fax your question to the NASA STI Help Desk at $443-757-5803$

- Telephone the NASA STI Help Desk at 443-757-5802

- Write to: NASA Center for AeroSpace Information (CASI) 7115 Standard Drive Hanover, MD 21076-1320 
NASA/TM-2012-217250

\section{PIV Measurements of Supersonic Internally-Mixed Dual-Stream Jets}

James E. Bridges and Mark P. Wernet

Glenn Research Center, Cleveland, Ohio

Prepared for the

17th Aeroacoustics Conference

cosponsored by the American Institute of Aeronautics and Astronautics and the Confederation of European Aerospace Societies

Portland, Oregon, June 5-8, 2011

National Aeronautics and

Space Administration

Glenn Research Center

Cleveland, Ohio 44135 


\section{Acknowledgments}

This work was supported by the Supersonics Project of the NASA Fundamental Aeronautics Program. The authors acknowledge the able efforts of their colleagues at the NASA AeroAcoustic Propulsion Lab.

Cliff Brown and Nick Georgiadis provided very helpful reviews of the work.

Trade names and trademarks are used in this report for identification only. Their usage does not constitute an official endorsement, either expressed or implied, by the National Aeronautics and Space Administration.

This work was sponsored by the Fundamental Aeronautics Program at the NASA Glenn Research Center.

Level of Review: This material has been technically reviewed by technical management.

Available from

NASA Center for Aerospace Information 7115 Standard Drive

Hanover, MD 21076-1320
National Technical Information Service 5301 Shawnee Road Alexandria, VA 22312

Available electronically at http://www.sti.nasa.gov 


\title{
PIV Measurements of Supersonic Internally-Mixed Dual-Stream Jets
}

\author{
James E. Bridges and Mark P. Wernet \\ National Aeronautics and Space Administration \\ Glenn Research Center \\ Cleveland, Ohio 44135
}

\begin{abstract}
While externally mixed, or separate flow, nozzle systems are most common in high bypass-ratio aircraft, they are not as attractive for use in lower bypass-ratio systems and on aircraft that will fly supersonically. The noise of such propulsion systems is also dominated by jet noise, making the study and noise reduction of these exhaust systems very important, both for military aircraft and future civilian supersonic aircraft. This paper presents particle image velocimetry of internally mixed nozzle with different area ratios between core and bypass, and nozzles that are ideally expanded and convergent. Such configurations independently control the geometry of the internal mixing layer and of the external shock structure. These allow exploration of the impact of shocks on the turbulent mixing layers, the impact of bypass ratio on broadband shock noise and mixing noise, and the impact of temperature on the turbulent flow field. At the 2009 AIAA/CEAS Aeroacoustics Conference the authors presented data and analysis from a series of tests that looked at the acoustics of supersonic jets from internally mixed nozzles. In that paper the broadband shock and mixing noise components of the jet noise were independently manipulated by holding Mach number constant while varying bypass ratio and jet temperature. Significant portions of that analysis was predicated on assumptions regarding the flow fields of these jets, both shock structure and turbulence. In this paper we add to that analysis by presenting particle image velocimetry measurements of the flow fields of many of those jets. In addition, the turbulent velocity data documented here will be very useful for validation of computational flow codes that are being developed to design advanced nozzles for future aircraft.
\end{abstract}

\section{Introduction}

The Supersonics Project at NASA has identified Airport Noise as one of the Technical Challenge areas for future civilian supersonic vehicles. The charter for this research thrust is to identify and mature relevant noise reduction technologies and engineering tools that will be required to create a commercially viable supersonic aircraft. Given that most paper studies point to moderate bypass ratio propulsion systems as being likely for such aircraft, one activity of the program has been to assure that appropriate flow and noise databases exist for this type of jet flow. While several acoustic datasets exist for single flow supersonic jets and many more for dual stream subsonic jets, there was a lack of data for supersonic dual stream jets. There was especially a dearth of flow field data, a big hole given the driving need for detailed data for validating advanced computational methods. Having been identified, a campaign was mounted to fill this hole in research data by building an internally mixed nozzle system with variable bypass area and multiple convergent-divergent nozzles, and making extensive acoustic and particle image velocimetry (PIV) measurements over a range of flow conditions. Along with a series of externally mixed nozzle flows this test was referred to as the Supersonic Dual Flow test, and it required multiple test entries over a three-year span to complete. The acoustic data were analyzed and presented in Reference 1; this paper primarily presents and analyzes the particle image velocimetry data, although corresponding acoustic results are given alongside for convenient reference.

For many years researchers have compared convergent-divergent and convergent nozzles to isolate broadband shock noise (BBSN), under the assumption that BBSN is independent of jet mixing noise 
(Refs. 2 and 3). That seems consistent with observations that low frequency noise stays the same for a given ideally expanded Mach number. The physical mechanism of BBSN seems well understood in that it involves the interaction of the standing pattern of flow inhomogeneities (shocks) with convecting turbulence. The fully expanded Mach number, $M$, give the shock strengths and spacings. The strength and spectral content of the turbulence in the shear layer is given by velocity gradient, $\partial U / \partial r$. Further, Tam's wavy wall analogy (Ref. 4) that successfully predicts the frequency shift of the peak BBSN, implicates the convection speed of the turbulence as having a major role in the source mechanism of BBSN. Consequently, BBSN is a function of Mach number $M$ and jet velocity $U$. Conventionally, BBSN has been assumed to be independent of jet temperature (Ref. 2), although recent papers have found some dependence (Ref. 3). Whether this is sensitivity to temperature or to shear velocity is not possible to ascertain since the two are tied for a given Mach number $M$.

The test matrix for the flow measurement portion of the Supersonic Dual Flow (SDF) test was created to study the following issues as they relate to the flow and noise of dual-stream jet flows:

1) Impact of splitter area ratio (Bypass Ratio)

2) Impact of shocks (Convergent versus Ideally Expanded Nozzles)

Objective 1 was addressed simply by changing the area ratio of the upstream splitter and running the same core and bypass pressure and temperature ratios. It was expected that there would be a major change in the structure of the turbulence associated with the difference in geometry of the shear layers. An alternative approach would have been to keep the mixed velocity constant, but that was not pursued since jet noise does not simply scale on mixed jet velocity. Of special interest was how splitter area ratio changed the turbulence in the shock cells and indeed the strength of the shocks themselves.

Objective 2 was addressed by testing convergent nozzles and ideally expanded nozzles at the same bypass ratio and flow condition. This was an important set of data because it documents how turbulence was affected by the shocks for a given flow condition. It has been observed that jet mixing noise is roughly the same with or without shocks, so the question was raised: is the turbulence also the same?

In discussion of the results, three jet noise components will be frequently mentioned: jet mixing noise, broadband shock noise (BBSN), and screech. Notionally, these are defined as shown in Figure 1. Another source of jet noise is nominally found in the cases presented in this paper, often referred to as Mach wave emission. This sound is associated with the large-scale instability waves or convecting eddies moving at supersonic speeds and producing sound that has strong directivity in the downstream direction.

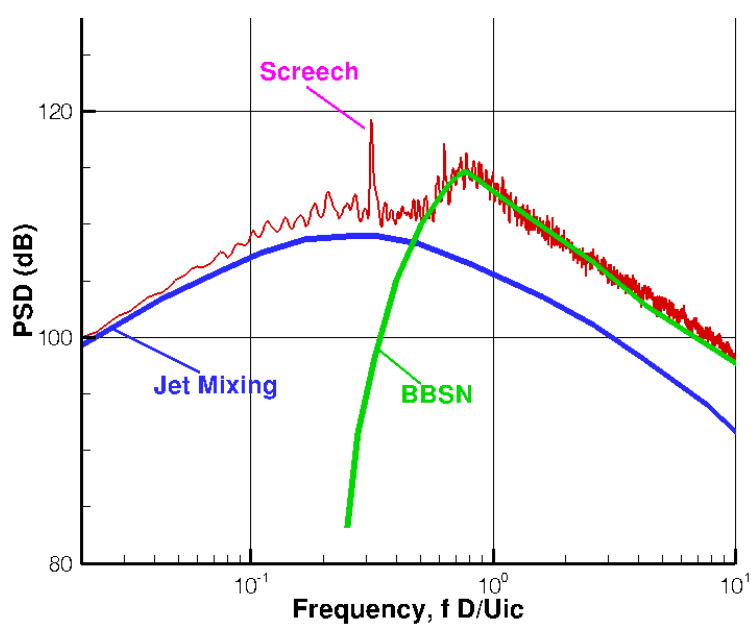

Figure 1.-Notional definition of jet noise sources as identified in acoustic spectra acquired at broadside angles. 


\section{Facility, Model Hardware, Instrumentation, and Flow Conditions}

\section{Model Hardware}

The test was conducted in the NASA Glenn Research Center AeroAcoustic Propulsion Laboratory (AAPL). The AAPL is a 65-ft radius anechoic geodesic hemispherical dome. Acoustic wedges covered the walls of the dome and the floor area of the test arena. The ambient temperature, pressure, and relative humidity were recorded within the dome.

The Nozzle Acoustic Test Rig (NATR) is a large, ejector-driven freejet used to generate forward flight airflow through its 53 in. (1.35 m) exit. Simulated flight speeds up to Mach 0.35 were produced through the acoustically lined tunnel.

The High Flow Jet Exit Rig (HFJER) was positioned at the end of the NATR, with the nozzle exit roughly 60 in. $(1.5 \mathrm{~m})$ downstream of the NATR exit plane. The HFJER delivered high-pressure air from the Center's compressed air system to the test article. Flow rates up to $25 \mathrm{lbm} / \mathrm{sec}$ are available in each of two streams. One of the streams passes through a natural gas-fired combustor that could heat the flow to approximately 1800R. The rig is instrumented with a 40-element charging station rakes in both core and bypass streams. The control system allows instantaneous calculation of total pressure ratio and total temperature ratio of both streams along with the deviation from the researcher-input conditions. In this way the flow conditions were held to keep jet velocities within 0.5 percent of the intended condition, including the simulated flight stream.

The test nozzles were attached to the aft end of the HFJER and are shown in Figure 2. The model system consisted of an interchangeable set of four axisymmetric splitters and four nozzles, all of exit diameter 4 in. (101.6 mm). The axisymmetric splitters yielded area ratios of 0.2 (S1), 1.0 (S2), 2.0 (S3) and 3.0 (S4), and terminate $6.5 \mathrm{in}$. (166 mm) upstream of the nozzle exit. The convergent-divergent nozzles were designed using the method of characteristics and tuned with RANS CFD to produce nearly perfectly expanded flows of Mach 1.18 (M2), 1.4 (M4), and 1.5 (M5). A center plug, required to achieve the highest area ratio, was varied in length and found to be inconsequential to the sound produced by the nozzles.

\section{Flow Conditions}

A series of flow conditions were defined that matched the design Mach numbers $M_{d}$ of the convergent-divergent nozzles while varying the temperature of the core to hit a common set of velocity ratios. (Even in the case of convergent nozzle flows, the fully expanded Mach number $M$ will be used.) In doing this the shock structure and turbulence intensities were to be independently varied. For this report a subset of these flow conditions are used and are documented in Table 1. Actual test conditions were specified in terms of nozzle pressure ratio (NPR) and total temperature ratios on core $\left(T_{t, c} / T_{\infty}\right)$ and bypass $\left(T_{t, b} / T_{\infty}\right)$ streams, respectively. Note that since both streams emerged inside the common nozzle, the pressure was the same on both streams for all setpoints. The table also lists ideally expanded velocities of the core $\left(U_{i c}\right)$, bypass $\left(U_{i b}\right)$, and mass-weighted fully mixed streams $\left(U_{i m}\right)$. 


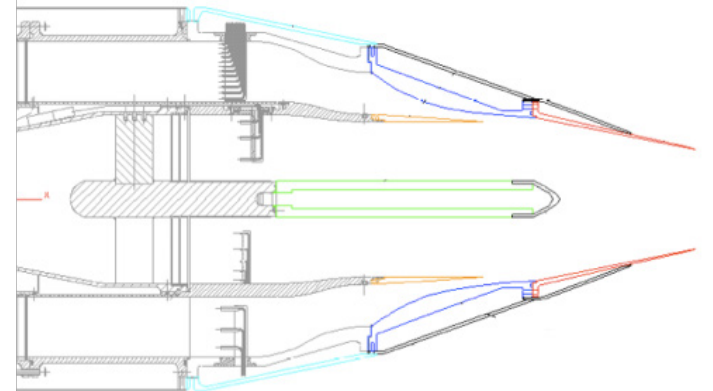

C4-S1

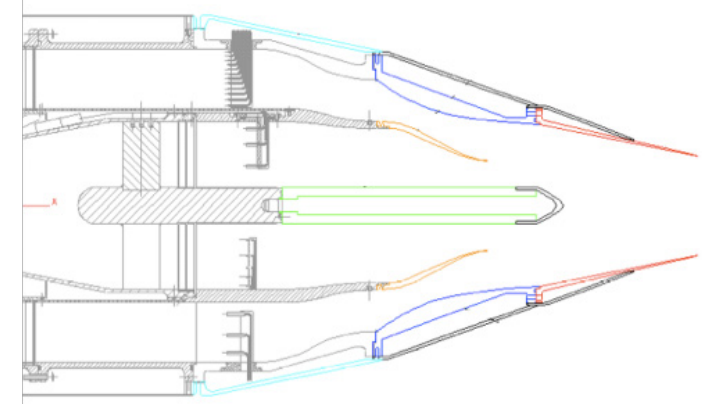

C4-S4

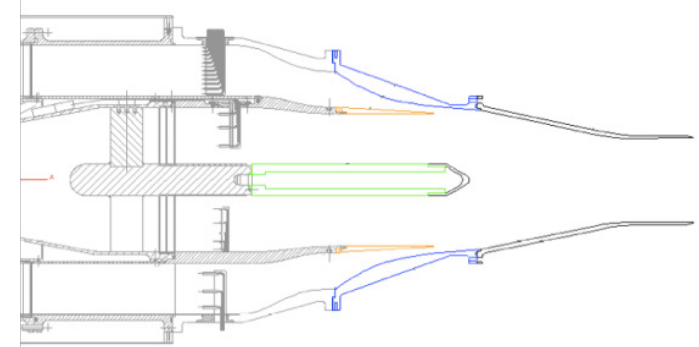

M2-S1

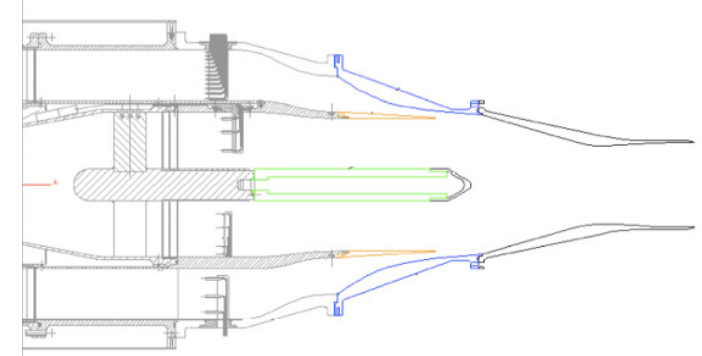

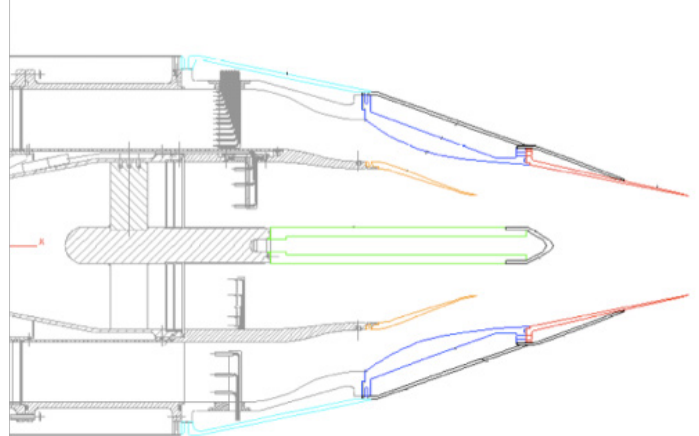

C4-S3

M5-S1

Figure 2.-Nozzles used in Supersonic Aeroacoustic Database. 
TABLE 1.-TEST MATRIX WITH NOZZLE ID AND FLOW CONDITIONS.

\begin{tabular}{|c|c|c|c|c|c|c|c|c|c|}
\hline Config & Setpoint & $M$ & NPR & $T_{t, c} / T_{\infty}$ & $T_{t, b} / T_{\infty}$ & $\mathrm{BPR}$ & $\begin{array}{l}U_{i c} \\
\mathrm{ft} / \mathrm{s}\end{array}$ & $\begin{array}{l}U_{i b}, \\
\mathrm{ft} / \mathrm{s}\end{array}$ & $\begin{array}{l}U_{i m}, \\
\mathrm{ft} / \mathrm{s}\end{array}$ \\
\hline C4S1 & 6010 & 1.0 & 1.89 & 0.99 & 0.99 & 0.21 & 1014.48 & 1016 & 1015 \\
\hline C4S1 & 6040 & 1.0 & 1.89 & 1.65 & 1.00 & 0.27 & 1311.86 & 1026 & 1256 \\
\hline C4S1 & 8020 & 1.2 & 2.43 & 1.23 & 1.17 & 0.20 & 1316.53 & 1287 & 1312 \\
\hline C4S1 & 8060 & 1.2 & 2.40 & 2.76 & 1.03 & 0.34 & 1973.04 & 1208 & 1810 \\
\hline C4S1 & 9020 & 1.4 & 2.42 & 1.23 & 1.19 & 0.20 & 1314.22 & 1294 & 1311 \\
\hline C4S1 & 9050 & 1.4 & 3.17 & 2.21 & 1.02 & 0.30 & 1971.44 & 1336 & 1845 \\
\hline C4S1 & 10020 & 1.5 & 3.67 & 1.23 & 1.19 & 0.20 & 1534.71 & 1514 & 1531 \\
\hline C4S1 & 10050 & 1.5 & 3.67 & 1.97 & 1.12 & 0.26 & 1971.04 & 1483 & 1880 \\
\hline C4S3 & 6040 & 1.0 & 1.88 & 1.67 & 0.99 & 2.96 & 1309.8 & 1011 & 1094 \\
\hline C4S3 & 8060 & 1.2 & 2.41 & 2.73 & 1.09 & 4.01 & 1977.61 & 1251 & 1425 \\
\hline C4S3 & 10060 & 1.5 & 3.66 & 2.48 & 1.16 & 3.36 & 2192.97 & 1497 & 1681 \\
\hline C4S4 & 6040 & 1.0 & 1.88 & 1.63 & 0.98 & 4.82 & 1311.8 & 1020 & 1076 \\
\hline C4S4 & 8060 & 1.2 & 2.40 & 2.71 & 1.10 & 6.29 & 1974.97 & 1260 & 1380 \\
\hline C4S4 & 9050 & 1.4 & 3.17 & 2.15 & 1.10 & 4.83 & 1977.1 & 1413 & 1524 \\
\hline C4S4 & 10050 & 1.5 & 3.67 & 2.00 & 1.15 & 4.37 & 1972.67 & 1492 & 1592 \\
\hline M2S1 & 8120 & 1.2 & 2.42 & 1.21 & 1.17 & 0.21 & 1314.39 & 1292 & 1311 \\
\hline M2S1 & 8130 & 1.2 & 2.43 & 1.64 & 1.03 & 0.25 & 1537.23 & 1220 & 1479 \\
\hline M2S1 & 8160 & 1.2 & 2.39 & 2.73 & 1.04 & 0.35 & 1969.93 & 1214 & 1804 \\
\hline M2S3 & 8130 & 1.2 & 2.42 & 1.64 & 1.09 & 2.70 & 1530.39 & 1247 & 1329 \\
\hline M2S3 & 8160 & 1.2 & 2.40 & 2.74 & 1.13 & 4.08 & 1970.83 & 1269 & 1433 \\
\hline M2S4 & 8130 & 1.2 & 2.43 & 1.68 & 1.13 & 4.05 & 1534.45 & 1259 & 1318 \\
\hline M2S4 & 8160 & 1.2 & 2.40 & 2.73 & 1.10 & 6.93 & 1974.89 & 1259 & 1370 \\
\hline M4S1 & 9120 & 1.4 & 3.17 & 1.34 & 1.28 & 0.20 & 1533.55 & 1495 & 1527 \\
\hline M4S1 & 9130 & 1.4 & 3.18 & 1.55 & 1.13 & 0.23 & 1645.27 & 1403 & 1603 \\
\hline M5S1 & 10120 & 1.5 & 3.68 & 1.21 & 1.16 & 0.21 & 1535.67 & 1504 & 1530 \\
\hline M5S1 & 10150 & 1.5 & 3.67 & 1.99 & 1.12 & 0.27 & 1974.27 & 1482 & 1879 \\
\hline M5S1 & 10170 & 1.5 & 3.64 & 2.96 & 1.12 & 0.35 & 2417.65 & 1483 & 2212 \\
\hline M5S4 & 10150 & 1.5 & 3.66 & 2.02 & 1.16 & 4.59 & 1973.6 & 1494 & 1590 \\
\hline M5S4 & 10170 & 1.5 & 3.64 & 3.01 & 1.16 & 6.63 & 2419.92 & 1498 & 1645 \\
\hline
\end{tabular}

\section{Far-Field Acoustic Instrumentation}

This report will cover both far-field acoustic spectral directivity and plume measurements using rakes of static pressure probes and total temperature probes. Acoustic measurements were recorded by an array of 24 microphones placed on an arc with a radius of $45 \mathrm{ft}(13.7 \mathrm{~m})$ at $5^{\circ}$ intervals from $45^{\circ}$ to $160^{\circ}$. The microphones were $1 / 4$ in. Bruel \& Kjaer model 3949 free-field type, pointed at the nozzle exit with the grid caps removed. Bruel \& Kjaer Nexus amplifiers provide the signal conditionings. Eight seconds of data are recorded at each point on a DataMAX Instrumentation Recorder (R.C. Electronics, Inc.) at $200 \mathrm{kHz}$ sample rate using a $90 \mathrm{kHz}$ low-pass filter to limit the bandwidth. After being corrected for amplifier gain, the prerecorded background sound levels were removed spectrally and actuator and free-field responses from the calibration facility were applied. Atmospheric attenuation was added back to the sound spectra using the formula of Shields and Bass (Ref. 5). In cases of simulated forward flight the refraction of the sound through the freejet shear layer was removed and the data were transformed to a consistent 100 jet-diameter distance assuming lossless spherical spreading, and interpolated to a consistent set of observer angles. The narrowband power spectral densities were further normalized using jet diameter and ideally expanded, fully mixed velocity to be presented as power spectral density as a function of Strouhal number. 


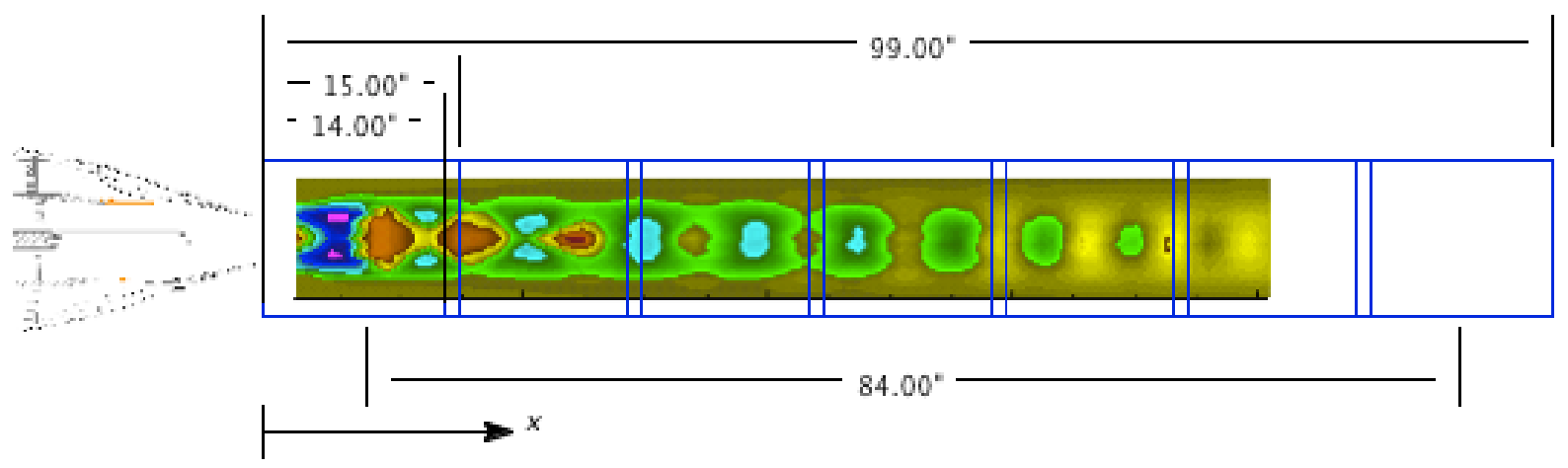

Figure 3.-Schematic for PIV acquisition strategy.

\section{PIV With Streamwise Light Sheet}

The particle image velocity (PIV) equipment was mounted on a large traverse that provided a moveable, common base for light sheet optics and cameras. $\mathrm{Al}_{2} \mathrm{O}_{3}$ seeders were used for the core and bypass streams along with a Rosco Delta 3000 glycol fogger to seed the ambient air with particles of approximately $0.5 \mu \mathrm{m}$.

The flow field was imaged using dual cameras positioned side-by-side at right angles to the jet axis, offset in axial distance, at a distance of 63 in. $(1.6 \mathrm{~m})$ from the jet centerline. Each camera imaged a field of view of 12 - by 8 -in. (30- by 20-mm), which with 1 in. ( $25 \mathrm{~mm}$ ) overlap, yielded an aggregate field of view of 12 in. $(30 \mathrm{~mm}$ ) vertical by 15 in. (38 mm) axial. This field of view was centered on the jet centerline. Acquisition went straight to disk in bursts of 400 frames at roughly $1 \mathrm{~Hz}$. The entire optical arrangement was traversed to 7 stations at a step size of 14 in. (35.5 mm) between acquisitions (84 in. $(2.13 \mathrm{~m})$ of travel), delivering flow field data roughly 99 in. $(2.51 \mathrm{~m})$ of flow field in all. This strategy is depicted in Figure 3. The nozzle was not in first field of view, but the traverse was moved far enough forward before the laser was operated to allow the first camera to image the nozzle and establish the reference after the rig reached its full thermal growth.

\section{Data Presentation}

In the presentation of results, the parameters of nozzle type, splitter area ratio, pressure ratio, and temperature ratio were shuffled to look at the impact of the different parameters in isolation. A series of figures have been prepared which combine flow field and acoustic data. The flow fields are represented by contour plots of mean and rms velocities. The acoustic far field of the jets is represented by the OASPL directivity and spectrum at $90^{\circ}$ to the jet axis.

For better cross-comparison of results, the flow field plots all used the same range in the contour levels. The mean axial velocity, $U / U_{i c}$, ranged 0 to 1.2 ; the rms of axial velocity, $u^{\prime} / U_{i c}$, ranged 0 to 0.185 . Both velocity quantities were normalized by ideally expanded core velocity. This normalization was chosen first to give a reasonable, consistent range for the mean velocity plots, and second in the belief that the TKE would scale on the mean gradients, starting with the peak velocity. This did seem to be a good choice as the peak TKE was fairly consistent for all setpoints and nozzle configurations. Other normalizations were explored, but for relating the flow to the sound for configurations that had a constant initial flow condition the ideally expanded core velocity seemed best.

Two plots of the acoustic far field of the jets are shown along with the mean and rms flow fields for each case. The spectra have been normalized to a 100 jet diameter distance, removing atmospheric attenuation, and expressed as normalized power spectral density in decibel, e.g., $20 \log _{10}((\mathrm{~Pa} / \mathrm{St}) / 20 \mu \mathrm{Pa})$, plotted as a function of Strouhal number $S t=f D / U_{i c}$. Note that similar to the flow normalization, the Strouhal number used in the sound power normalization was the ideally expanded core velocity. Again, other choices of normalization could be used but as explained in the Discussion section this choice was most widely useful. 
Discussion accompanying the presentation of data attempts to relate the flow and acoustic data. To do this the approximation is made that the jet mixing noise at right angles to the jet scales roughly as $U^{8}$ for jets of the speed range measured here. For subsonic jets acoustic analogy theory indicates that the noise also scales with turbulent kinetic energy to the $7 / 2$ power, producing a scaling with rms velocity $u^{\prime} / U$ of $70 \log _{10}\left(u^{\prime} / U\right)$. No attempt is made to correlate the aft angle noise, which can be dominated by mach wave emission at the highest speeds shown here, with the flow data.

\section{Results}

\section{Impact of Splitter Area Ratio (0.2 - 3.0)}

In this section jets of the same nozzle and flow conditions, but different splitter area ratios, are compared. Bear in mind that with a common nozzle, the pressures on the two streams are necessarily equal, meaning that an increase in the core velocity temperature translates into higher velocity in the core stream. It is important to remember that the flow data have been normalized by the common core velocity $U_{i c}$. This makes the plots of mean flows have significant similitude near the nozzle, but means that farther downstream where the flows are dissimilar the dominant mean gradients are given more by equivalent mixed velocity. This scaling does not present the flows on an equal thrust basis-that would require normalizing by mass-averaged velocity instead.

For example, in Figure 4, the convergent nozzle is run at $M=1$ with a warm core flow using three different splitters to achieve three different bypass ratios. The mean velocity fields show a normalized potential core velocity of approximately 1.0 near the nozzle exit. Recall that the splitter between hot and cold flows terminates approximately 1.5 nozzle diameters upstream of the nozzle exit. In the mean flow profiles at $x / D=0.25$ the thin cold flow from the splitter C4S1 configuration has already merged with the hot core flow, the nozzle exit being 23 times the cold flow annulus radii downstream. In the C4S2 and C4S3 flow profiles the lower velocity cold flow is clearly discernable even at $x / D=2$, although they are not easily distinguished from one another. Inspection of the turbulence profiles at $x / D=0.25$ shows a hint of the inner shear layer just inside the common outer shear layer in the C4S1 profile.

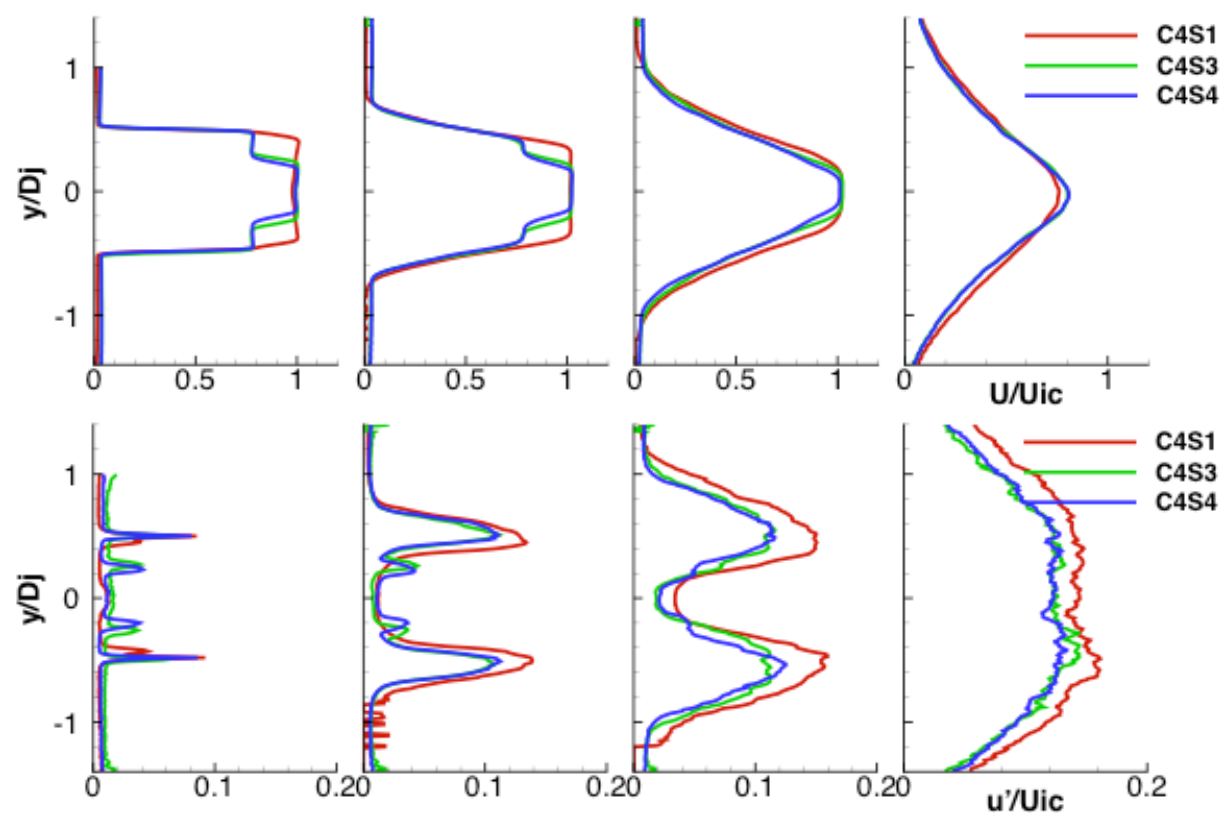

Figure 4.-Transverse profiles of mean (top) and rms (bottom) velocities for convergent nozzle C4 with different splitter area ratios (setpoint 6040; $M=1.0, T_{t, c} / T_{\infty}=1.65$ ). 


\section{Ideally Expanded Nozzles}

Ideally expanded flows do not contain strong shocks making them better for exploring the impact that bypass ratio has on the flow and noise. To get a feel for the variations being made to the flow, consider the velocity profiles measured near the nozzle exit when the ideally expanded $M=1.19$ jet is operated with three different core temperatures, shown in Figure 5. The increase in core temperature at a fixed pressure ratio results in an increase in core velocity, shown clearly in the flow profiles from the S4 splitter geometry. In the first case (setpoint 8020), the two streams are run at approximately the same temperature and there is only a shear layer on the nozzle lip line. In the second case (setpoint 8030), the core is heated slightly and a second shear layer emerges, much weaker that the one on the nozzle lip line. In the third case (setpoint 8060), the inner shear layer is over half the strength of the outer one.

The first ideally expanded flow to be examined is actually a subsonic jet from the conic nozzle C4 operating at $M=1.0$, shown in Figure 6. The mean flow shows no evidence of shock cells and has a potential core ending around $x / D=8$. The rms of the axial velocity peaks near the lipline radially, broadly around the end of the potential core, at roughly $u^{\prime} / U_{i c}=0.15$. This is in keeping with a wide range of subsonic jets measured previously (Ref. 6).

Now heat is added to the core stream, keeping the pressures of the two streams the same, set at $M=$ 1.0 (Figure 7). In the case of splitter area ratio $=0.2$ (top plots of Figure 7) the two shear layers merge almost immediately downstream of the nozzle and the rms velocity levels are approaching 0.17 . The jets with higher area ratios are roughly 5 percent longer, and have peak rms velocity levels that only reach 0.14 . In the jets with higher bypass area ratios the initial shear layers have much less turbulence intensity as each is driven by the velocity gradient between the cold flow and the ambient rather than the hot flow and ambient. Downstream of the merger between the hot and cold flows, where the turbulence is expected to scale on the fully mixed velocity, the low area ratio jet has higher fully mixed velocity and correspondingly higher turbulence levels, while the splitter area ratio 2 and 3 jets, being nearly matched in mixed velocity, have nearly matched turbulence levels.

Only the S1 and S3 splitter configurations were measured acoustically for this flow condition, and these are presented in Figure 7. The overall sound pressure level is approximately $4 \mathrm{~dB}$ louder for the jet with area ratio $=0.2$ than the one with area ratio $=2$ at polar angle of $90^{\circ}$. Given that the mass-averaged mixed velocities of the two jets were $1256 \mathrm{ft} / \mathrm{s}$ and $1095 \mathrm{ft} / \mathrm{s}$ respectively, a $5 \mathrm{~dB}$ difference would be expected around $90^{\circ}$ using $\mathrm{U}^{8}$ scaling on the fully mixed velocities. This is also in line with what would be expected from the difference in peak $u^{\prime} / U_{c}$ of 0.17 and 0.14 using $\left(u^{\prime} / U\right)^{7}$ scaling.

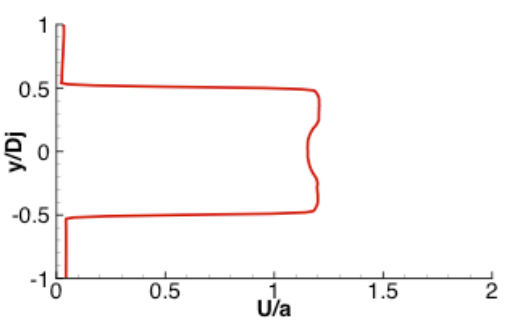

(a)

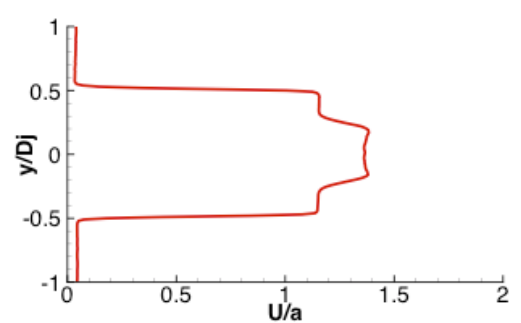

(b)

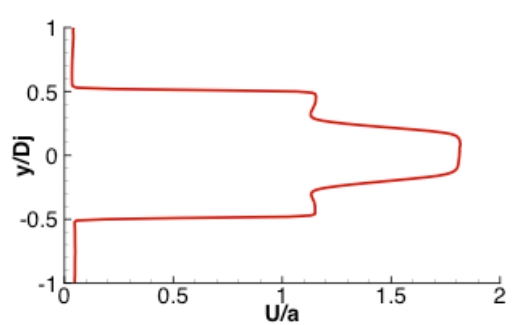

(c)

Figure 5.-Mean velocity profiles, normalized by ambient speed of sound, at $x / D=0.2$, for fully expanded $M=1.19$ jets with different core temperature ratios (setpoints) (a) $T_{t, c} / T_{\infty}=1.23$ (8020), (b) $T_{t, c} / T_{\infty}=1.64$ (8030), (c) $T_{t, c} / T_{\infty}=2.76$ (8060).

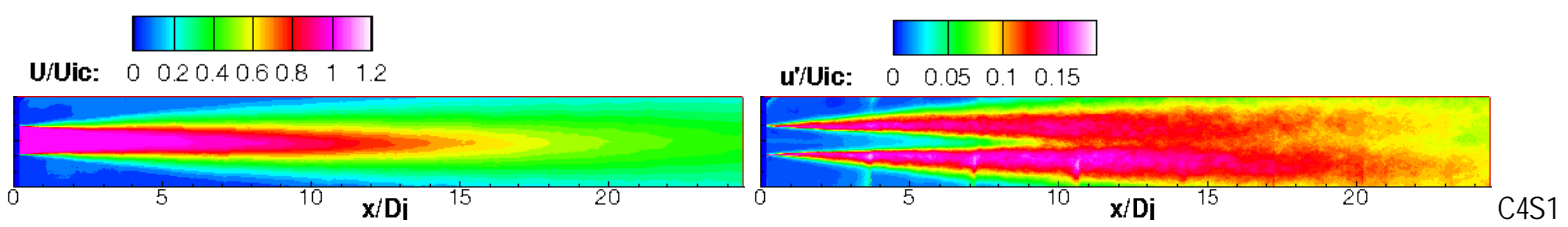

Figure 6.-Convergent nozzle C4S1 at cold subsonic flow (setpoint 6010; $\mathrm{M}=1.0, T_{t, c} / T_{\infty}=T_{t, b} / T_{\infty}=1.0$ ). 

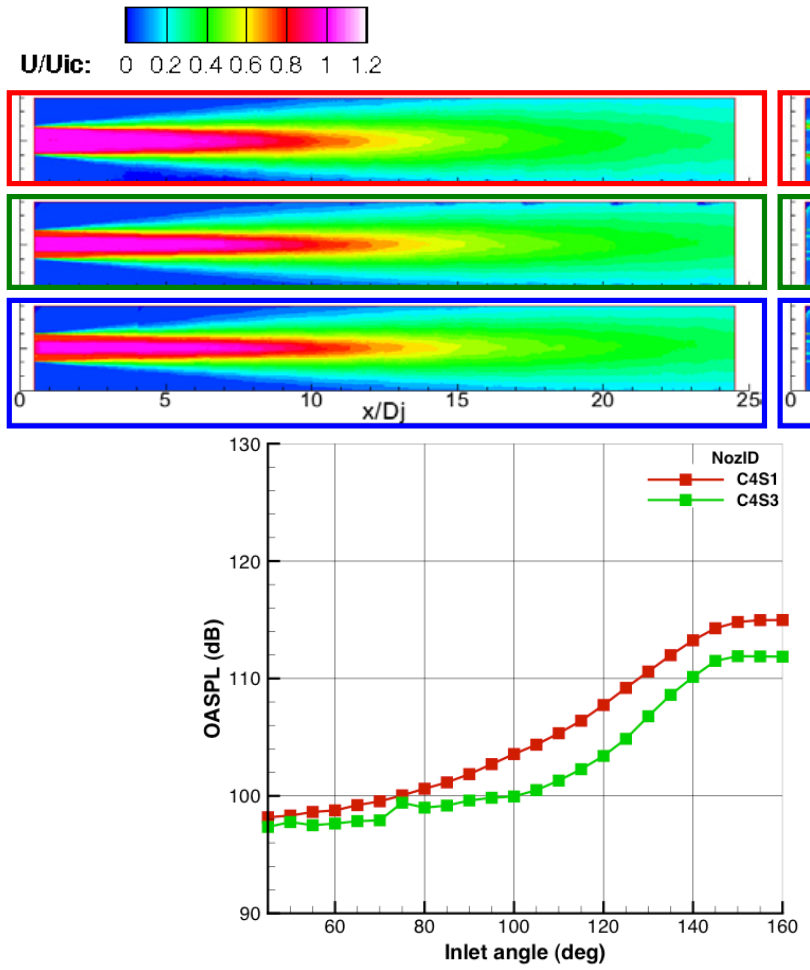

u'/Uic: $\quad 0 \quad 0.05 \quad 0.1 \quad 0.15$
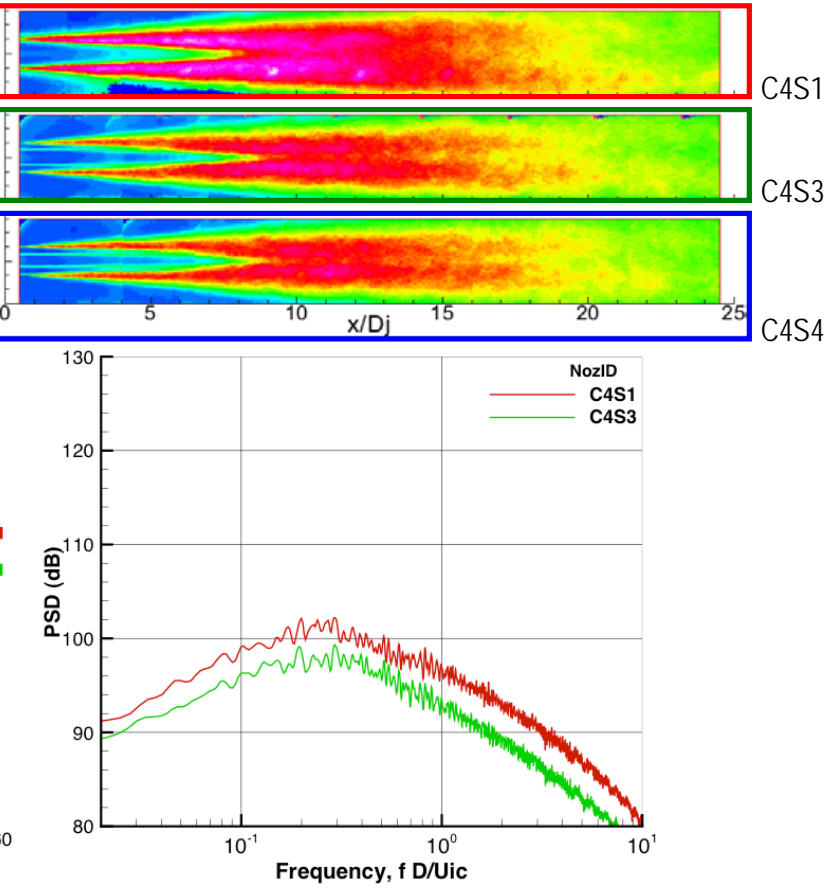

Figure 7.-Convergent nozzle C4, various splitter area ratios: 0.2 (S1), 2 (S3), 3 (S4) (setpoint 6040; $M=1.0$, $\left.T_{t, c} / T_{\infty}=1.65\right)$.
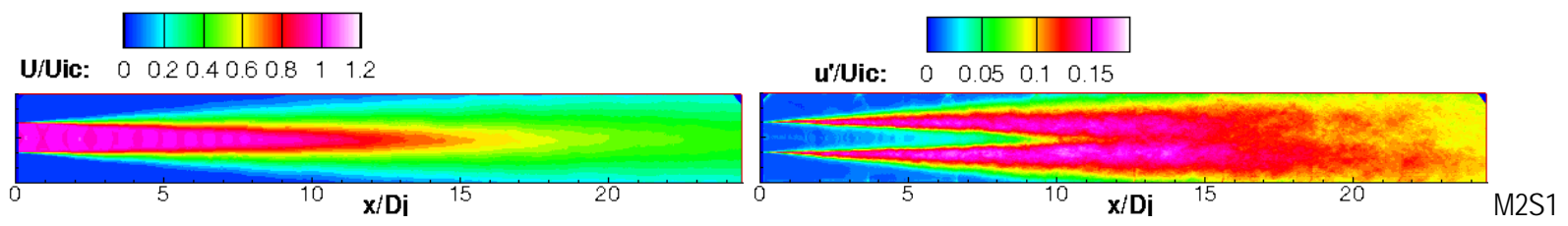

Figure 8.-Ideally expanded nozzle M2S1 (setpoint 8120; $M=1.19, T_{t, c} / T_{\infty}=1.21$ ).

In preparation for looking at velocity data corresponding to varying splitter area ratios at $M=1.19$ (setpoints 8130 and 8160), first consider the velocity fields from the M2S1 nozzle operating at this Mach number but with the same temperature on both stream (setpoint 8120) where the splitter should make no difference to the flow. In Figure 8 it is observed that even with this ideally expanded nozzle being operated at its design condition there are still slight shock cells present in the mean velocity contour plot. The end of the potential core occurs around $x / D=10$. This is also shown in the plot of the turbulence intensity, where the peak turbulence level is around 16 percent.

Next, consider how the $M=1.19$ flow changes when the core is moderately heated and how this change depends upon the splitter geometry, specifically the splitter area ratio. In Figure 9 the M2 nozzle again has barely perceptible shock cells in the mean velocity flows, and the potential core of the core stream is essentially the same for all splitter geometries. The rms velocity fields are also very similar in shape as the outer shear layer dominates the production of turbulence. While the turbulent velocity plots are very similar in shape, the peak turbulence intensity reduces with increase in splitter area ratio, from 0.15 in the M2S1 flow to 0.13 in the M2S4 configurations. Note that this is a steady reduction in peak turbulence level with increase in the outer flow thickness, starting with the single-flow case (Figure 8).

This trend in turbulence fields is reflected in the far-field noise. The OASPL directivities of the configurations are very similar, with the M2S1 being louder than the M2S3 and M2S4 by 2 and $3 \mathrm{~dB}$, respectively. The 3 and $4 \mathrm{~dB}$ decrease in OASPL at $90^{\circ}$ for S3 and S4 relative to S1 respectively is a 

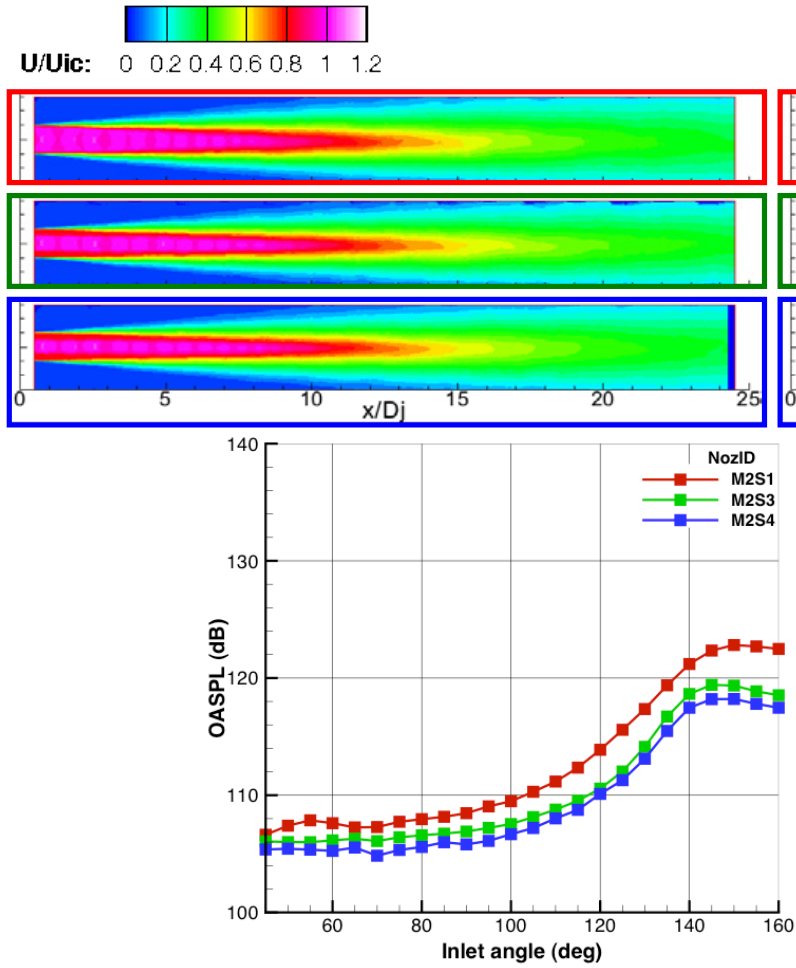

u'/Uic: $\quad \begin{array}{llll}0 & 0.05 & 0.1 & 0.15\end{array}$
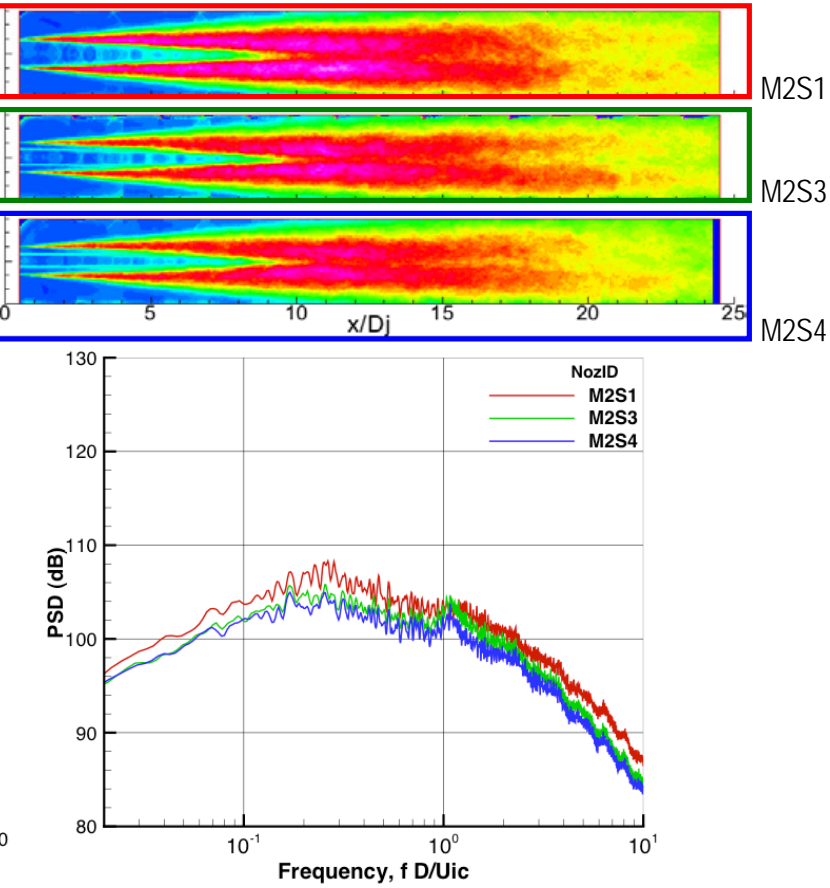

Figure 9.-Ideally expanded nozzle M2 various splitter area ratios: 0.2 (S1), 2 (S3), 3 (S4) (setpoint 8130; M=1.19, $\left.T_{t, c} / T_{\infty}=1.64\right)$.

bit less than the 8 and $9 \mathrm{~dB}$ expected from the fully mixed velocities, listed in Table 1 . It is also a bit less than what would be expected by the small variation in peak $u^{\prime} / U_{i c}$. The spectra at $90^{\circ}$ show very minimal BBSN, if any, and have the same shapes, varying only in amplitude.

The next dataset, in Figure 10, keeps the same Mach number, but increases the core temperature, and hence velocity. As seen in Figure 5, this also results in the inner shear layer becoming comparable to the outer shear layer in overall strength.

The flows are again nearly free of shocks and now the increase in the gradient of the inner shear layer causes the jet with the low splitter area ratio to have a much stronger turbulent velocity field (peaking near $\left.u^{\prime} / U_{i c}=0.16\right)$ than the jets with larger splitter area ratio $\left(u^{\prime} / U_{i c} \sim 0.13\right)$. The turbulence distribution is very different as well, with the strong inner shear layer moving the peak turbulence toward the centerline with increase in splitter area ratio.

For all the changes to the turbulence distribution, the OASPL directivities of the different splitter configurations are remarkably similar at the broadside angles, especially M2S1 and M2S3 which are virtually identical. To see differences in the acoustic fields at these angles corresponding to the differences in the turbulence distributions, one has to look at the spectra. There is a hint of BBSN in the spectra, with a slight hump at $S t=1$, most pronounced in the M2S3 configuration. At frequencies below the peak, frequencies presumed to come from the jet mixing noise component, the M2S1 splitter is $3 \mathrm{~dB}$ louder than the M2S3 and M2S4 splitter configurations, correlating with the increased turbulence measured. Near the spectral peak the M2S3 splitter configuration is loudest by $2 \mathrm{~dB}$, while the M2S1 and M2S4 configurations are exactly the same. At the highest frequencies the M2S1 is again louder, perhaps correlating with the higher turbulence in the shear layer of that configuration in the first few jet diameters. These subtle variations in what appear to be mixing noise are not easily associated with the differences in the turbulent fields of the jets. Also not obvious from the contour plots of $u^{\prime} / U_{i c}$ is the sharp spike in OASPL directivity at $130^{\circ}$ for the M2S3 configuration. This strong directivity is what has been attributed to Mach wave emission and does not correlate with the turbulence directly. 

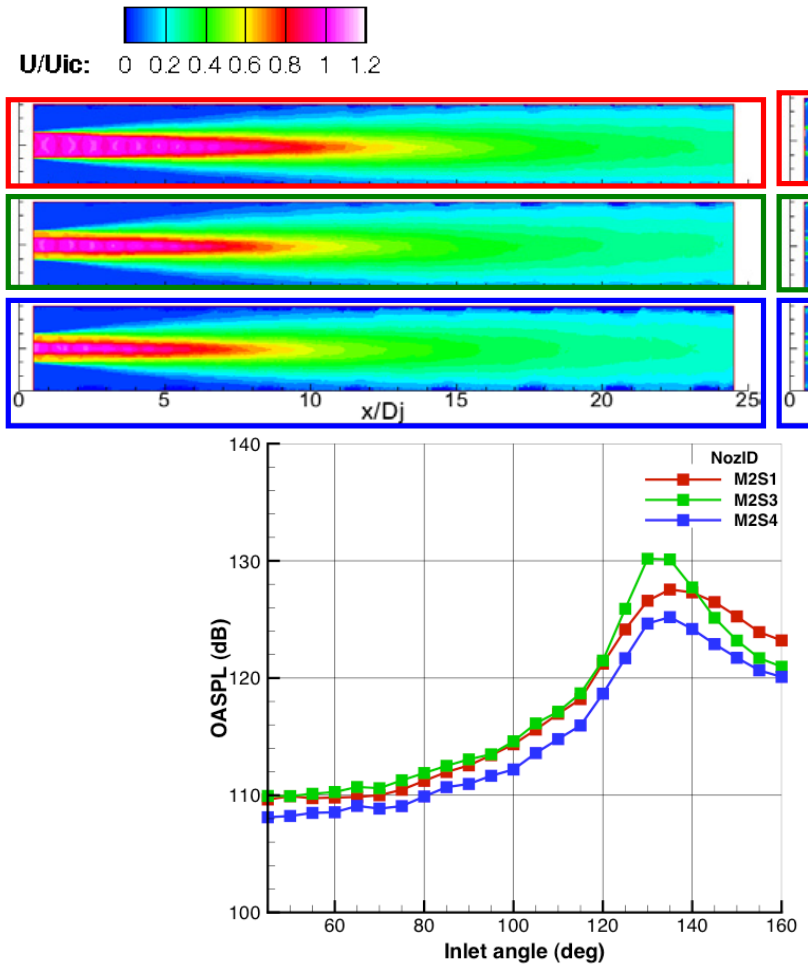

u'/Uic: $\quad \begin{array}{llll}0 & 0.05 & 0.1 & 0.15\end{array}$
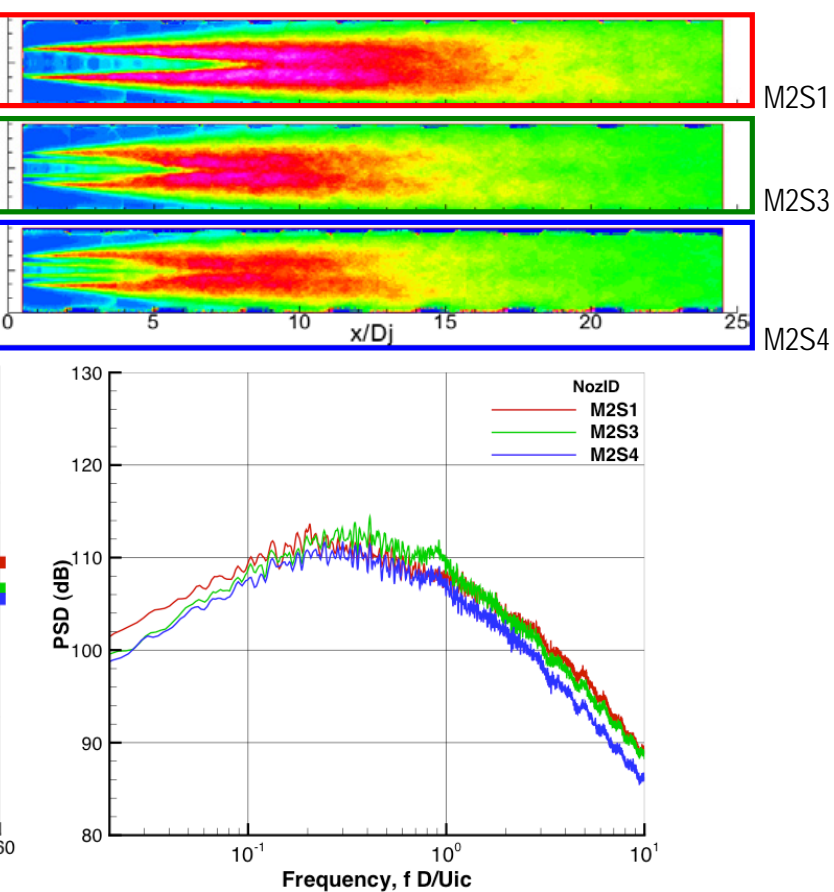

Figure 10.-Ideally expanded nozzle M2, various splitter area ratios: 0.2 (S1), 2 (S3), 3 (S4) (setpoint 8160; M=1.19, $\left.T_{t, c} / T_{\infty}=2.73\right)$.

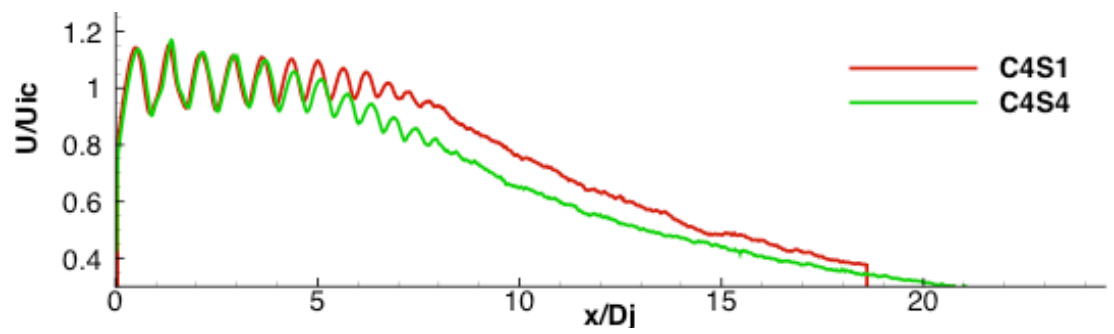

Figure 11.-Mean velocity along centerline plume of convergent nozzle C4 with splitter area ratios of 0.2 (S1) and 3 (S4) (setpoint 9050; $M=1.4, T_{t, c} / T_{\infty}=2.21$ ).

\section{Convergent Nozzle}

Now that the general trends of supersonic jets with varying bypass ratio have been shown, the complication of shocks is introduced. However, before diving into the flow and noise data in depth, one aspect of the underexpanded jets should be kept in mind: the shock cell lengths are only weakly dependent upon the temperature or the splitter geometry (Ref. 1). This is somewhat surprising given that the cells are established by reflection of the shocks from the velocity discontinuity at the shear layer, an aspect of the jet flow which is very strongly distorted by changes to the splitter geometry. Granted, the gradient from the outer shear layer was always greater than that from the inner in these experiments, but it seemed reasonable to expect some change in the shock cell geometry with changes in the inner shear layer strength and location. But this was not the case. Consider Figure 11, which shows centerline velocity profiles for the underexpanded convergent nozzle with the smallest and largest area ratio splitters. The flow is unchanged in the potential core, and the shock cell spacing only varies slightly after the mean flow begins to decay. 


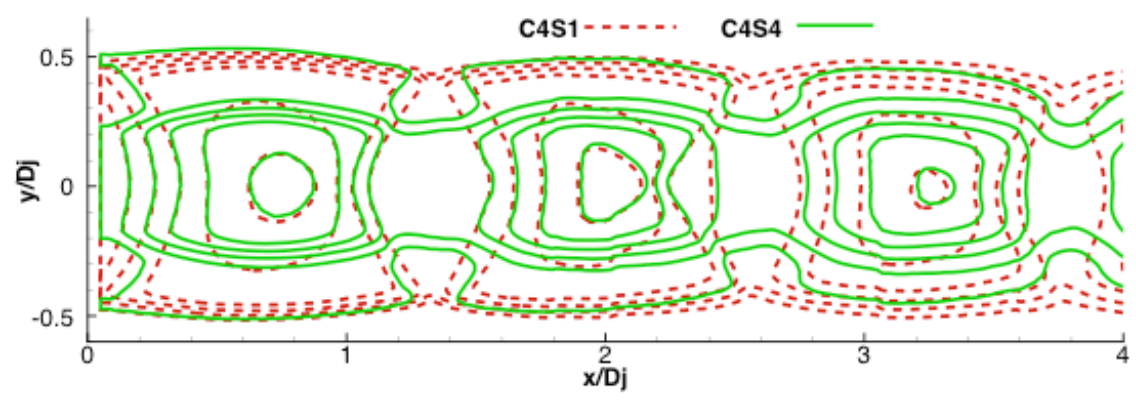

Figure 12.-Contours of mean velocity, detailing shock structure of convergent nozzle C4 with splitter area ratios of 0.2 (S1) and 3 (S4) (setpoint 9050; $\left.\mathrm{M}=1.4, T_{t, c} / T_{\infty}=2.21\right)$.

More detail of the shock structure in the presence of the inner shear layer is provided in Figure 12. The interplay of velocity gradients between the expansion fans and the shear layers are surprisingly independent, accounting for the insensitivity of the shocks to the inner shear layer.

The same three configurations as were explored above in Figure 7 are now presented in Figure 13, only with an increase in pressure ratio that yields $M=1.19$ flow. Shock cells appear in the mean velocity contours of the jet flows as a result of the underexpansion of the pressure at the nozzle exit. At this flow condition there is again enhanced turbulence in the jet with low area ratio splitter, as was seen in the ideally expanded jets, but the potential core of the low area ratio splitter is not much longer than the jets with high area ratio splitters. With the relatively large change in inner shear layer location there is a fundamental change in the distribution of the turbulence as the splitter ratio is changed, with very little turbulence in the initial outer shear layers, and a much shorter region of strong turbulence.

Acoustically, the OASPL at $90^{\circ}$ does not reflect the change in the turbulence levels between the various splitters cases, having essentially only a 1 to $2 \mathrm{~dB}$ change in overall sound level. However, this is a case where the equalities are fortuitous. Spectrally, the three jets have almost identical BBSN spectra beyond the first peak, where the C4S3 nozzle has a significantly greater peak than the other two. The jet mixing noise corresponds more with the levels of turbulence observed in the rms contour plots, the C4S1 nozzle being 3 and $5 \mathrm{~dB}$ louder than the C4S3 and C4S4 configurations, respectively. The C4S3 reaches roughly the same level as the C4S1 by virtue of its high BBSN peak. The equality of the BBSN spectra are not understood in light of the strong difference in turbulence in the shear layers. There was no screech measured from any of these flow configurations.

Changing to setpoint 9050 brings about an increase in pressure ratio and a slight reduction in core temperature, increasing the cold flow velocity while maintaining the hot core velocity. As seen in Figure 14 , this increase in pressure ratio increases the strength of the shocks, but again the shock cells lengths are not changed by the change in splitter geometry. Also, the jet with low area ratio splitter has a longer potential core. With an increase in velocity gradient on the outer shear layer relative to the inner shear layer, the turbulence contour plots of the C4S1 (area ratio $=0.2$ ) and C4S4 (area ratio $=3$ ) are very similar, both driven by the outer shear layer. The jet from the high area ratio configuration has reduced turbulence in the initial shear layer region, but has only slightly less volume of high intensity turbulence and a peak level within 10 percent of the C4S1 configuration.

Looking at OASPL is very misleading as there is significant BBSN present in the acoustic far field, a fact made plain in plot of spectra in Figure 14. Again, the BBSN spectra seem to match pretty closely, including the peak. The jet mixing noise components differ by some $5 \mathrm{~dB}$, a difference not expected based simply on the similarity of the turbulence levels in the two jets downstream of the potential core.

Neither configuration at this flow condition exhibited screech. 


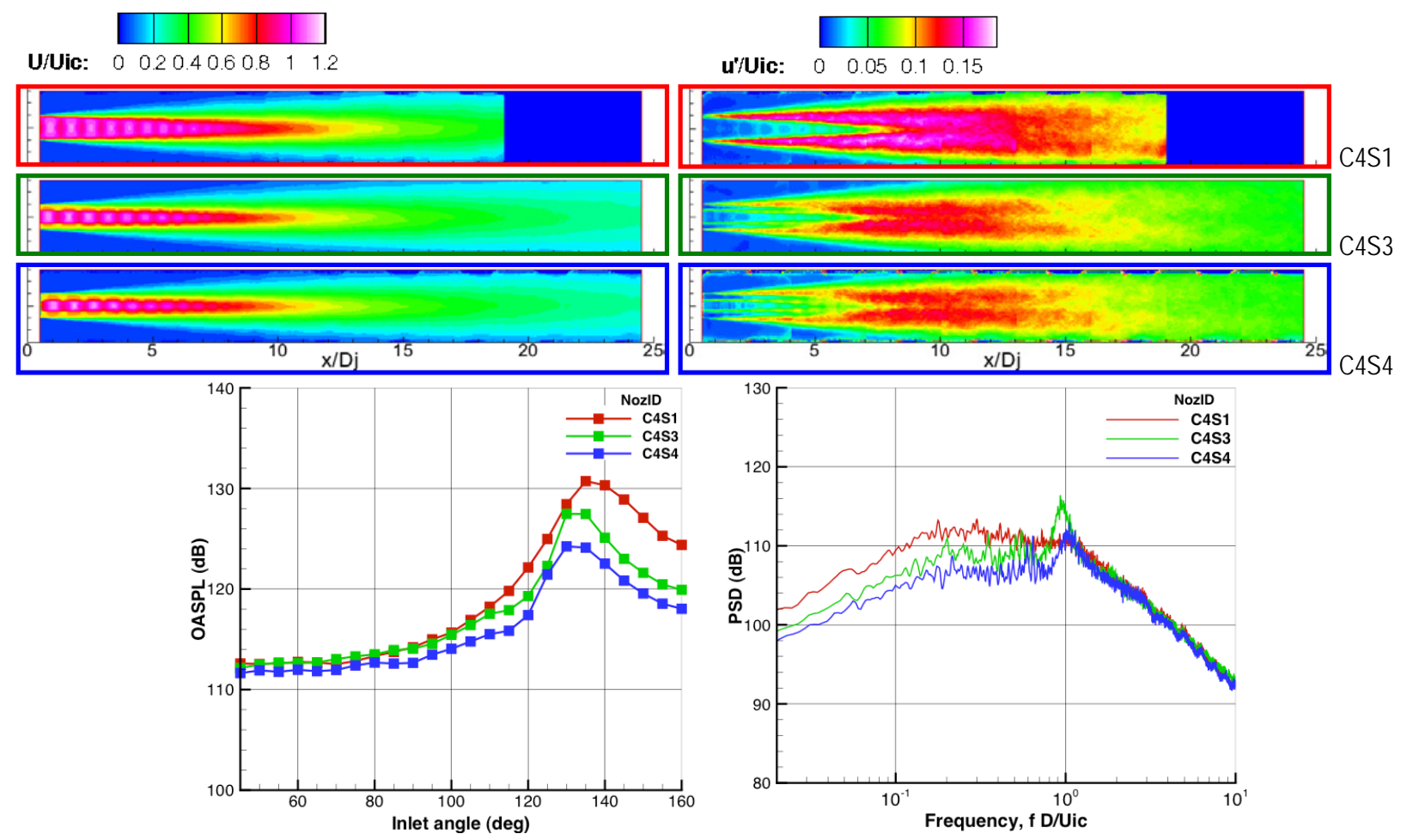

Figure 13.-Convergent nozzle C4, various splitter area ratios: 0.2 (S1), 2 (S3), 3 (S4) (setpoint 8060; $M=1.19$, $\left.T_{t, c} / T_{\infty}=2.73\right)$.

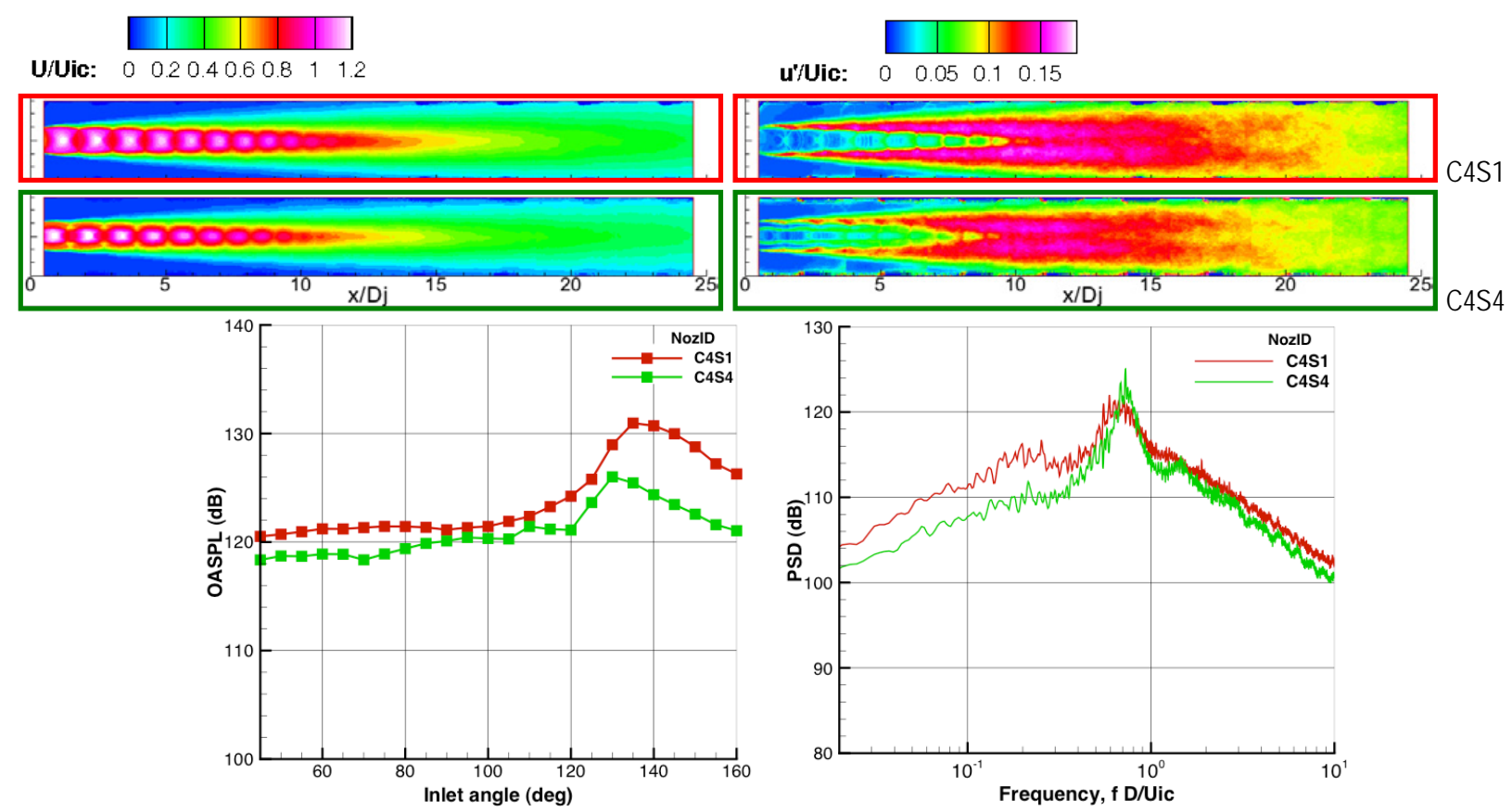

Figure 14.-Convergent nozzle C4, various splitter area ratios: 0.2 (S1), 2 (S3), 3 (S4) (setpoint 9050; M=1.4, $\left.T_{t, c} / T_{\infty}=2.21\right)$. 


\section{Impact of Shock on Turbulence and Noise (Convergent Versus Ideally Expanded Nozzles)}

During the presentation of the flow and noise from the ideally expanded (shock-free) and convergent nozzle systems there were several allusions to comparisons between two. This is natural since this would address the question of the impact of shocks on the flow and noise. To better facilitate this investigation, direct comparisons of the two nozzles will be made for the same splitter and flow condition.

\section{Splitter Area Ratio $=0.2$}

The comparison of shocked and shock-free flows will begin with the case of minimal bypass ratio, e.g. splitter area ratio $=0.2$. Of all the ideally expanded nozzles the $M_{d}=1.19$ convergent-divergent nozzle is the worst at being shock-free; hence there is a slight hint of shock cells in the velocity contours of the M2 nozzle shown in Figure 15. Of course, these shocks are very weak compared with those found in the convergent nozzle flow. Correspondingly, there is also a small amount of broadband shock noise (BBSN) that shows above the expected pure jet mixing noise in the spectra. Besides having a distinctive BBSN hump in its spectra there is a very small amount of screech in the convergent nozzle noise spectrum.

Looking at the contour plots of $u^{\prime} / U_{i c}$, the distribution of turbulence at the end of potential core is similar, but the shear layer is quite a bit thicker up front in the convergent, or shocked jet, and the potential core is slightly shortened by the enhanced mixing. The ideally expanded M2S1 nozzle has peak rms velocity levels of roughly 16 percent, compared to 15 percent for the convergent nozzle.

The increase in turbulence is reflected in the spectra where the jet mixing component is $1 \mathrm{~dB}$ or so higher for the ideally expanded nozzle. At broadside angles the BBSN of the convergent nozzle dominates the acoustic spectra and makes the OASPL significantly higher. At aft angles the OASPL of the convergent-divergent nozzle is higher. It is tempting to say that the increase in turbulence and the corresponding jet mixing noise increase is responsible. Perhaps this is true for this relatively low Mach number, but in higher Mach number jets to be shown below the correlation between peak turbulence and aft angle noise does not hold.
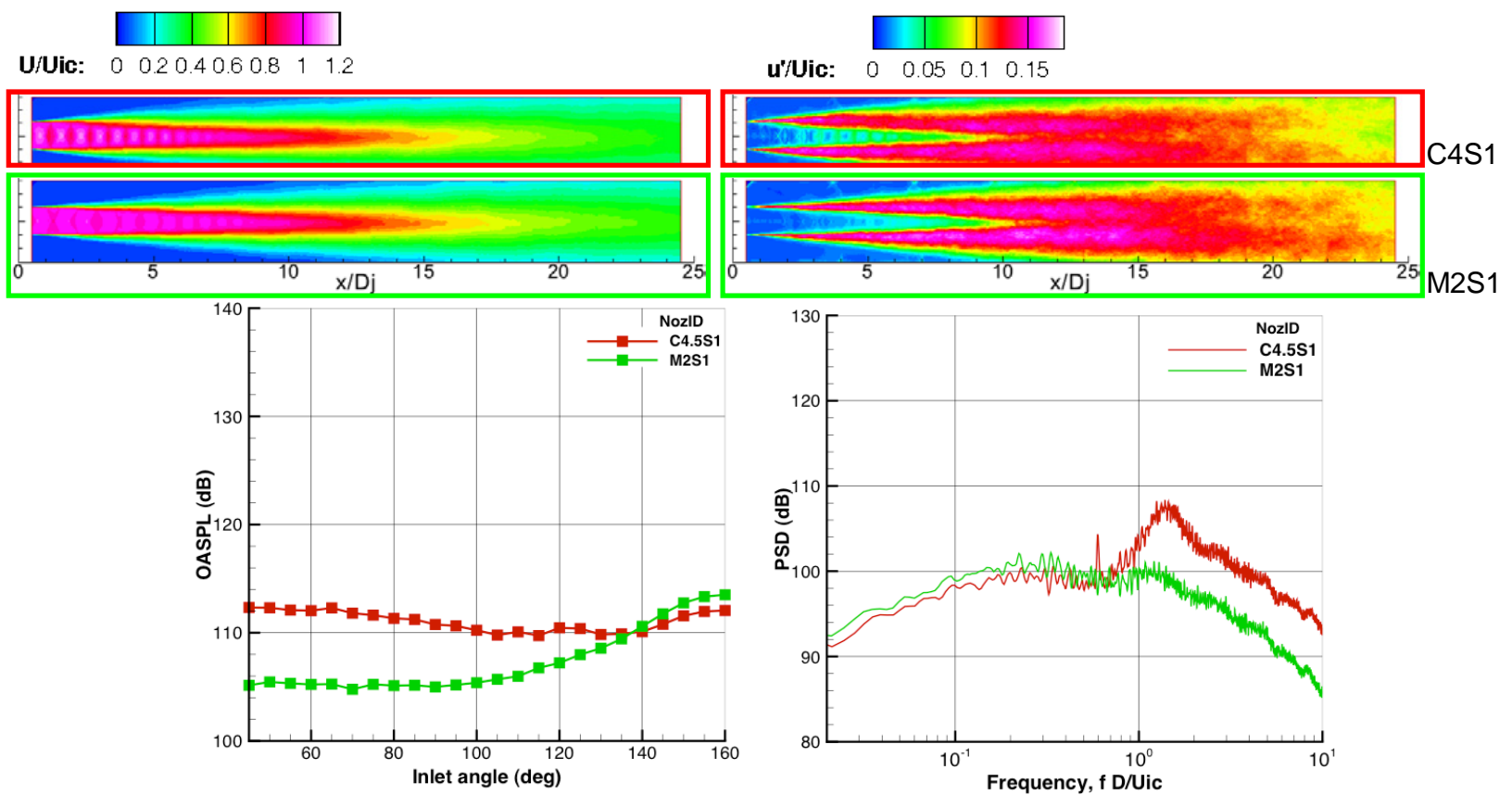

Figure 15. - Splitter area ratio $=0.2$, convergent C4 versus convergent-divergent M2 nozzles (setpoint 8020; $\left.M=1.19, T_{t, c} / T_{\infty}=1.23\right)$. 


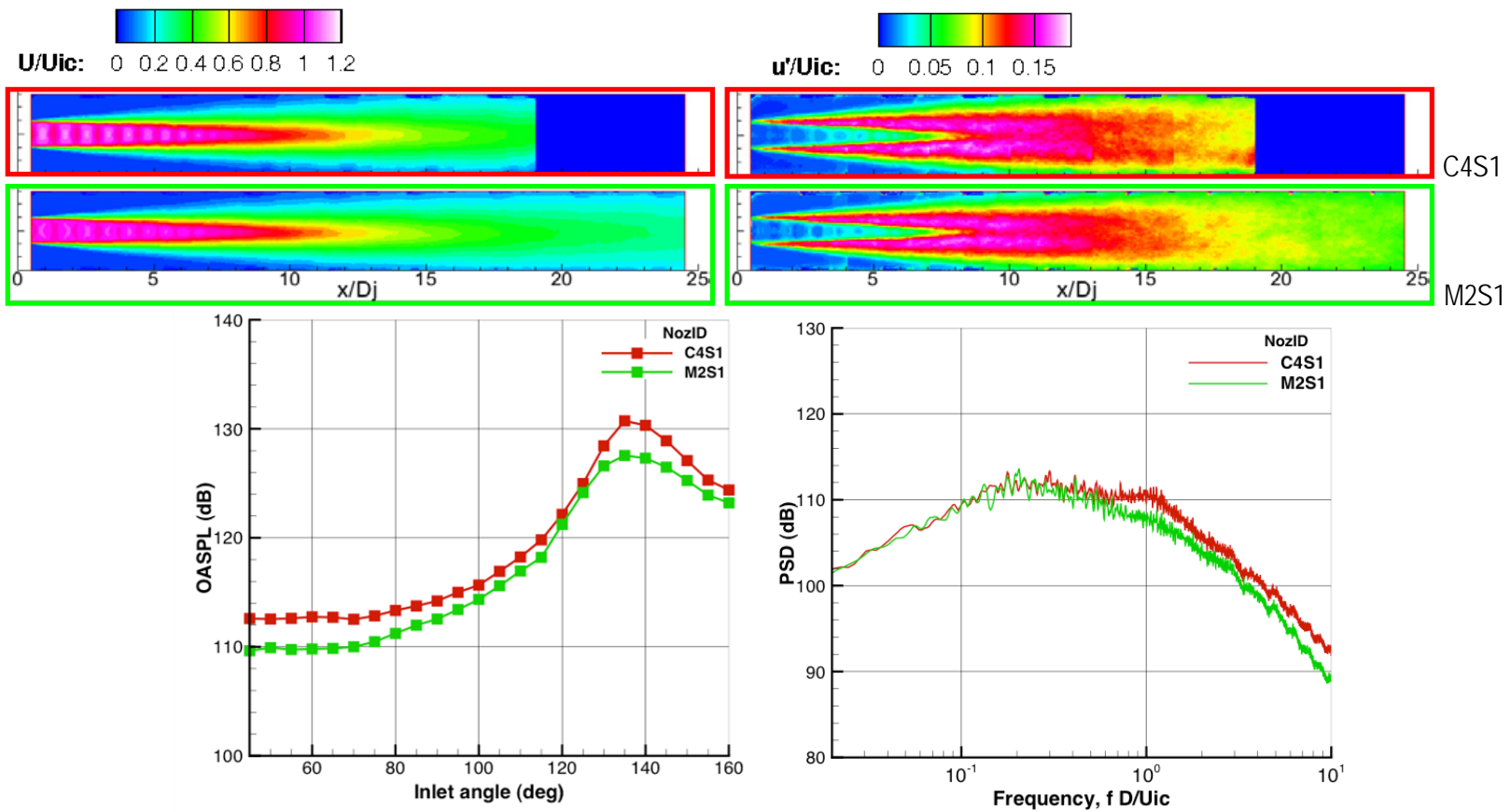

Figure 16. - Splitter area ratio $=0.2$, convergent $C 4$ versus convergent-divergent M2 nozzles (setpoint 8060; $\left.M=1.19, T_{t, c} / T_{\infty}=2.76\right)$.

The hotter M=1.19 jets in Figure 16 have flow fields that are very similar to each other, e.g., the potential core lengths, peak turbulence levels, and the shear layer thicknesses. Their acoustic fields are also very similar, with only a slight amount of BBSN in the convergent nozzle showing above the jet mixing noise. Compared with the sound spectra in Figure 15 the BBSN of the convergent nozzle is roughly the same amplitude (peaking near $109 \mathrm{~dB}$ ) but the jet mixing noise has increased to make it less noticeable. The lack of screech is understood to be due to the jet velocity being too high to support the feedback relationship required to match acoustic waves propagating upstream and instability waves convecting downstream (Ref. 7).

The isothermal $M=1.4$ jet (Figure 17) is considered next. The convergent nozzle has the expected shock cell pattern for this underexpanded flow condition, and has a slightly shorter potential core length than the ideally expanded jet. The ideally expanded nozzle has only the slightest shock cells discernable in the mean velocity contour plots. Looking at the turbulent velocity fields, the convergent nozzle again has an initial shear layer that is quite a bit thicker than the ideally expanded nozzle. The downstream turbulence levels are comparable at $u^{\prime} / U_{i c}=0.15$. The thicker initial shear layers, and hence greater mixing, probably account for the reduced potential core length.

Acoustically, the ideally expanded nozzle shows little if any sign of BBSN, whereas the convergent nozzle shows both strong BBSN and screech. The jet mixing noise at polar angle $90^{\circ}$ is a bit louder for the convergent nozzle, a result that is at odds with the similarity in the turbulence measured in the downstream portions of the two jets. More of an anomaly is the $4 \mathrm{~dB}$ increase in the OASPL of the convergent-divergent nozzle at the far aft angles. This was forewarned above, and is presumably caused by a difference in the convection velocity and hence strength of the Mach wave emission which begins to dominate the aft angle noise at this Mach number.

Similar trends hold for the flow fields when the Mach number is increased to $M=1.5$ (Figure 18) using a convergent-divergent nozzle designed for this Mach number (M5). The convergent nozzle has strong shock cells, BBSN, and screech. The convergent-divergent nozzle has only very faint shock cells and no significant BBSN. Again the initial shear layer of the convergent nozzle is thicker than the ideally expanded nozzle flow, and the potential core of the convergent nozzle is 10 to 15 percent shorter than that of the ideally expanded nozzle. The turbulence levels, and perhaps more notably the volume of 
turbulence, at the end of the potential core are reduced somewhat in the M5 nozzle with a corresponding reduction in the jet mixing component of the acoustic spectrum. Interestingly, the OASPL of the convergent-divergent nozzle remains lower than that of the convergent nozzle at the far aft angles, unlike the $M=1.4$ case above.
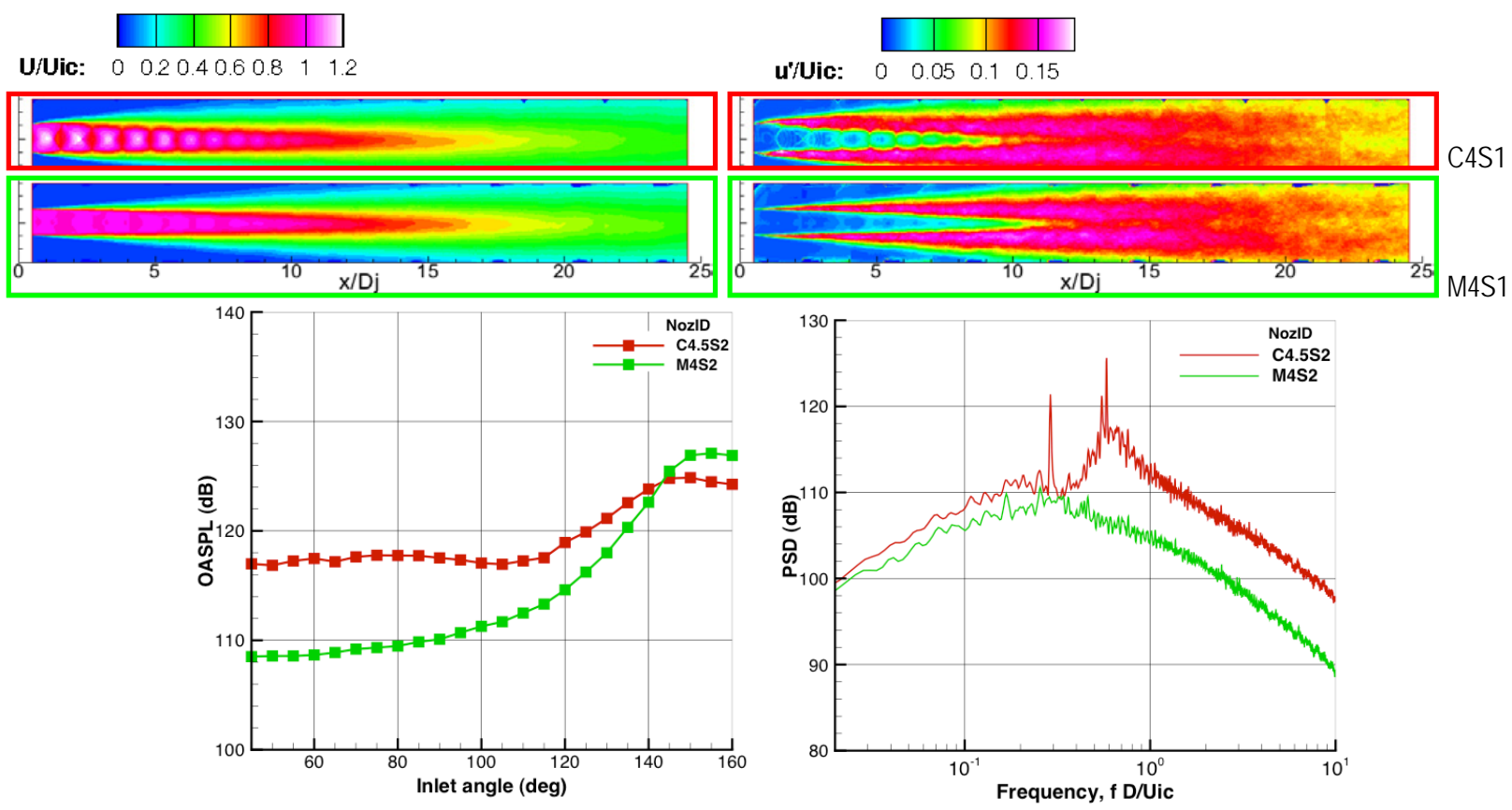

Figure 17.-Splitter area ratio $=0.2$, convergent $\mathrm{C} 4$ versus convergent-divergent M4 nozzles (setpoint 9020; $\left.M=1.4, T_{t, c} / T_{\infty}=1.23\right)$

U/Uic: 0
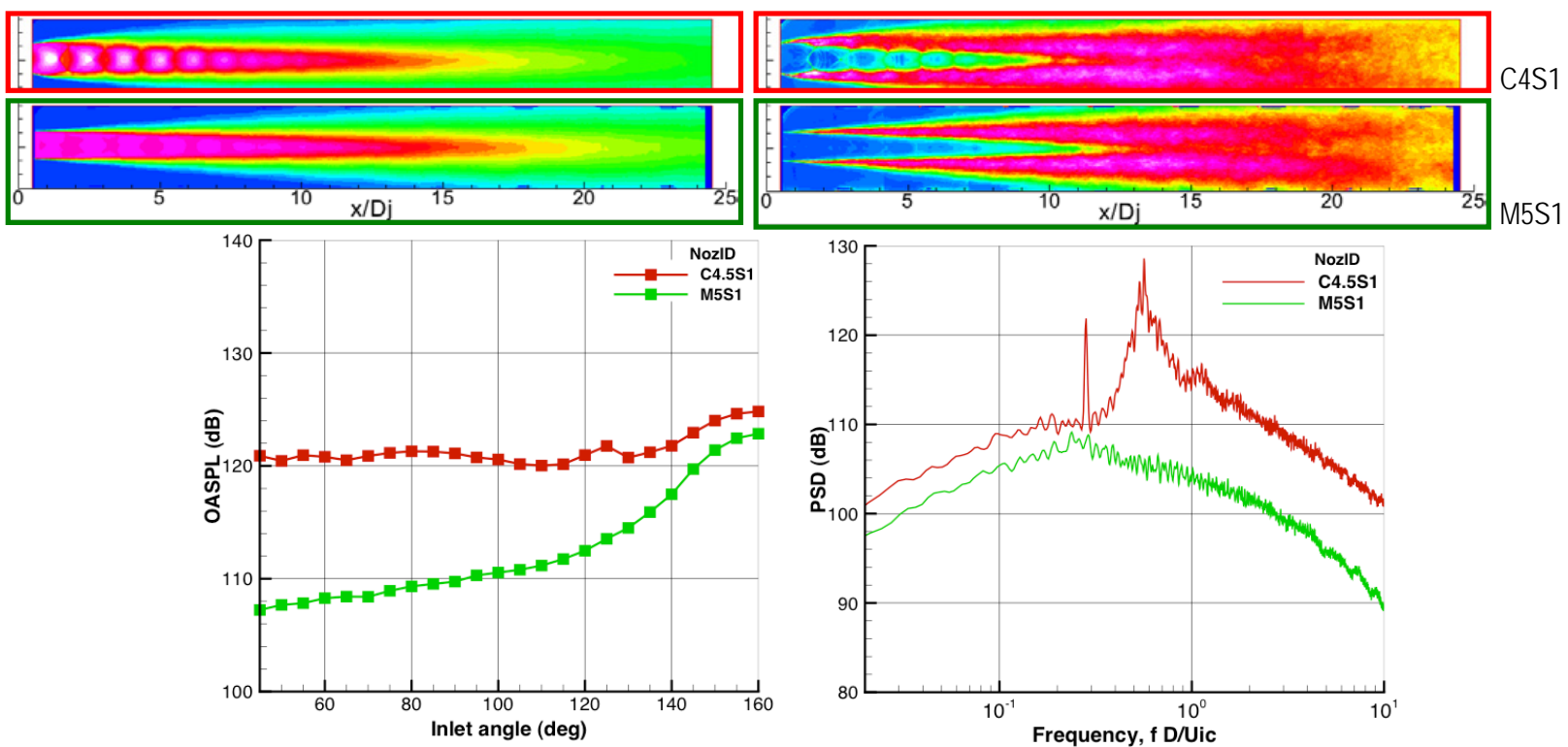

Figure 18. - Splitter area ratio $=0.2$, convergent C4 versus convergent-divergent M5 nozzles (setpoint 10020; $\left.M=1.5, T_{t, c} / T_{\infty}=1.23\right)$. 

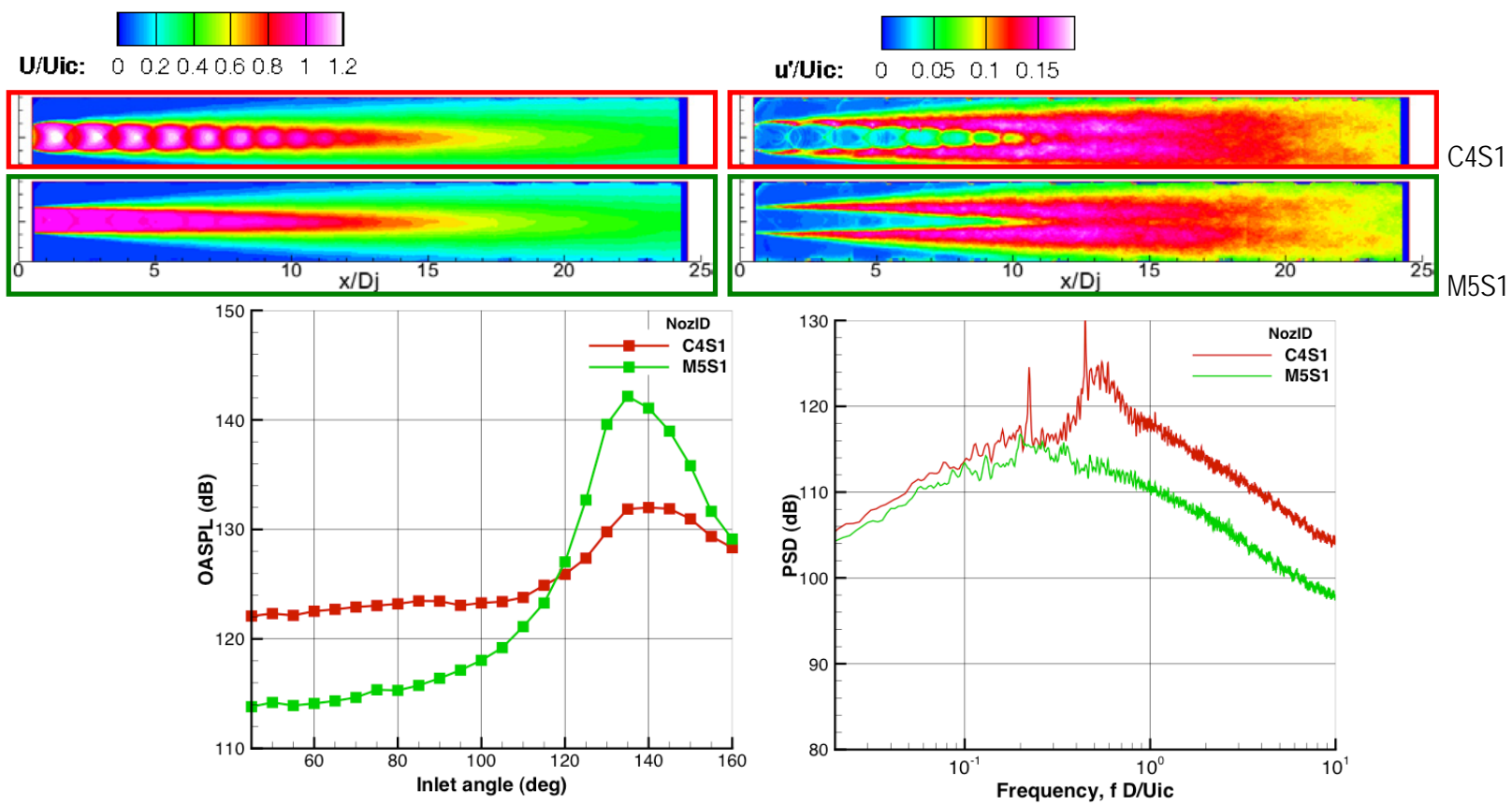

Figure 19. - Splitter area ratio $=0.2$, convergent C4 versus convergent-divergent M5 nozzles (setpoint 10050; $\left.M=1.5, T_{t, c} / T_{\infty}=1.97\right)$.

When the $M=1.5$ jet is heated (Figure 19) the strong shock cells remain present in the convergent nozzle flow, but the shear layer is not as thick. In fact, it has become strongly distorted by the shock cells. The potential core difference has also disappeared. In the acoustic spectra, the convergent $M=1.5$ hot jet has some screech, presumably because the temperature is not quite high enough to remove the feedback condition. The turbulence at the end of the potential core is just slightly less in the ideally expanded jet, which seems to correspond to the $1 \mathrm{~dB}$ reduction of the jet mixing noise component in the noise spectra at $90^{\circ}$. Note how the OASPL in the aft angles are very strongly changed by the nozzle. There is very strong peak noise downstream of the convergent-divergent nozzle relative to the shocked jet.

\section{Splitter Area Ratio = 2.0}

When the splitter area ratio is increased from 0.2 to 2.0, the outer sheath of cold flow become much more substantial. There is a significant length of internal shear layer between the core and bypass flows, and this brings about a strong change in the shape of the turbulence in the jet plume. And this change is different for the convergent and ideally expanded nozzle flows.

This change can be seen right away (Figure 20) for the hot $M=1.19$ jets from convergent $C 4$ and ideally expanded M2 nozzles. Focusing on the differences between convergent and ideally expanded nozzles, we note a significant shift in the potential core and in the axial distribution of turbulence. The ideally expanded flow actually has slightly higher peak turbulence levels $\left(u^{\prime} / U_{i c}=0.15\right.$ versus 0.13 for the convergent nozzle), a fact reflected in the slightly elevated peak jet mixing noise of the broadside acoustic spectrum. This is different from the case of splitter area ratio $=0.2$ in Figure 16 .

In comparison with the splitter area ratio $=0.2$ case, the convergent jet noise spectrum shows a bit more BBSN, mostly because the mixing noise, which presumably scales on the fully mixed velocity, is reduced with the increase in cold fan flow. There is still no sign of screech in this hot jet case. The OASPL directivity is somewhat complicated by the BBSN, for while the jet mixing noise is greater in the convergent-divergent nozzle at all angles, the BBSN elevates the OASPL at upstream and broadside polar angles. 


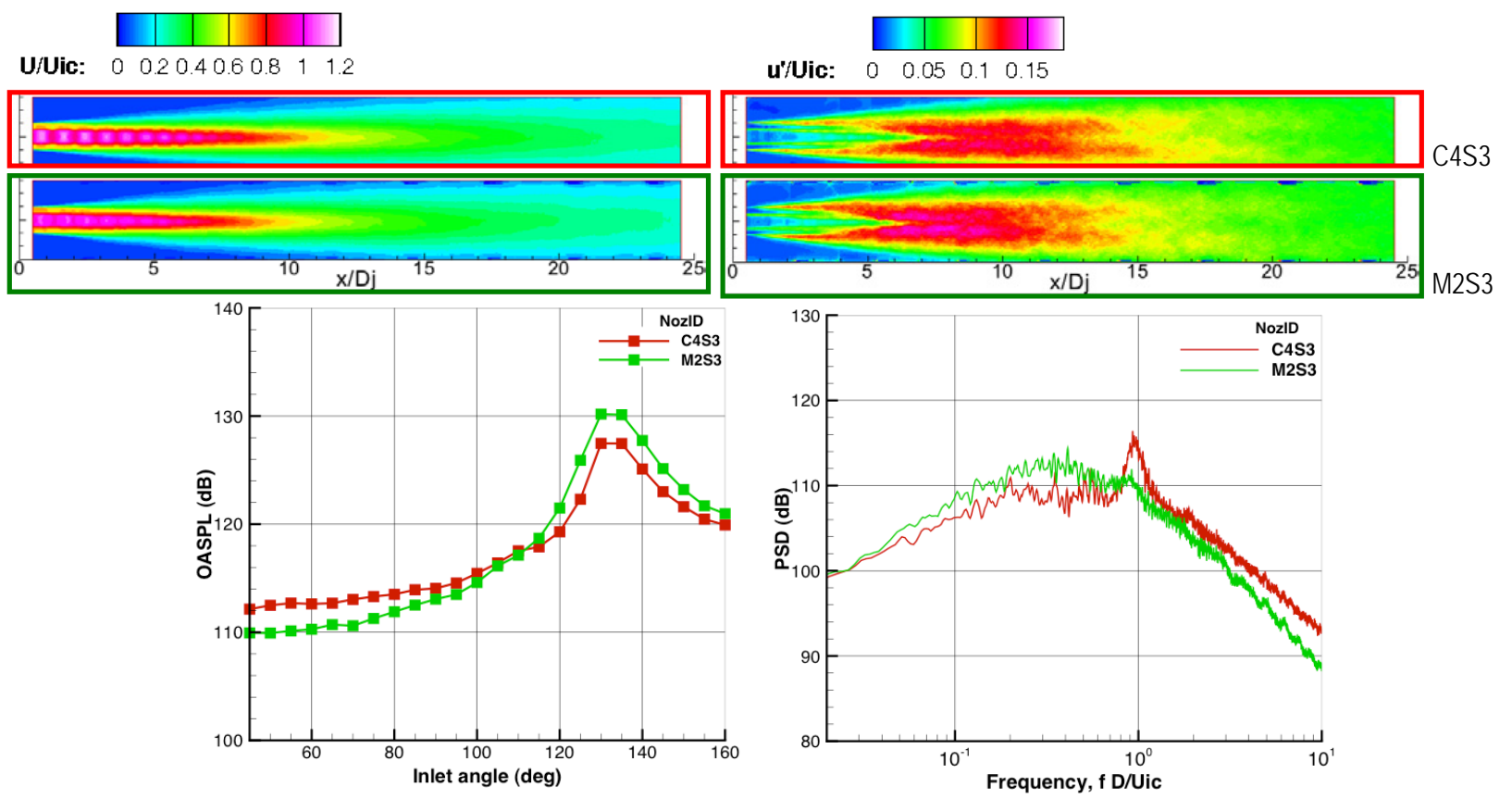

Figure 20.-Splitter area ratio $=2$, convergent C4 versus convergent-divergent M2 nozzles (setpoint 8060; $M=1.19$, $\left.T_{t, c} / T_{\infty}=2.76\right)$.

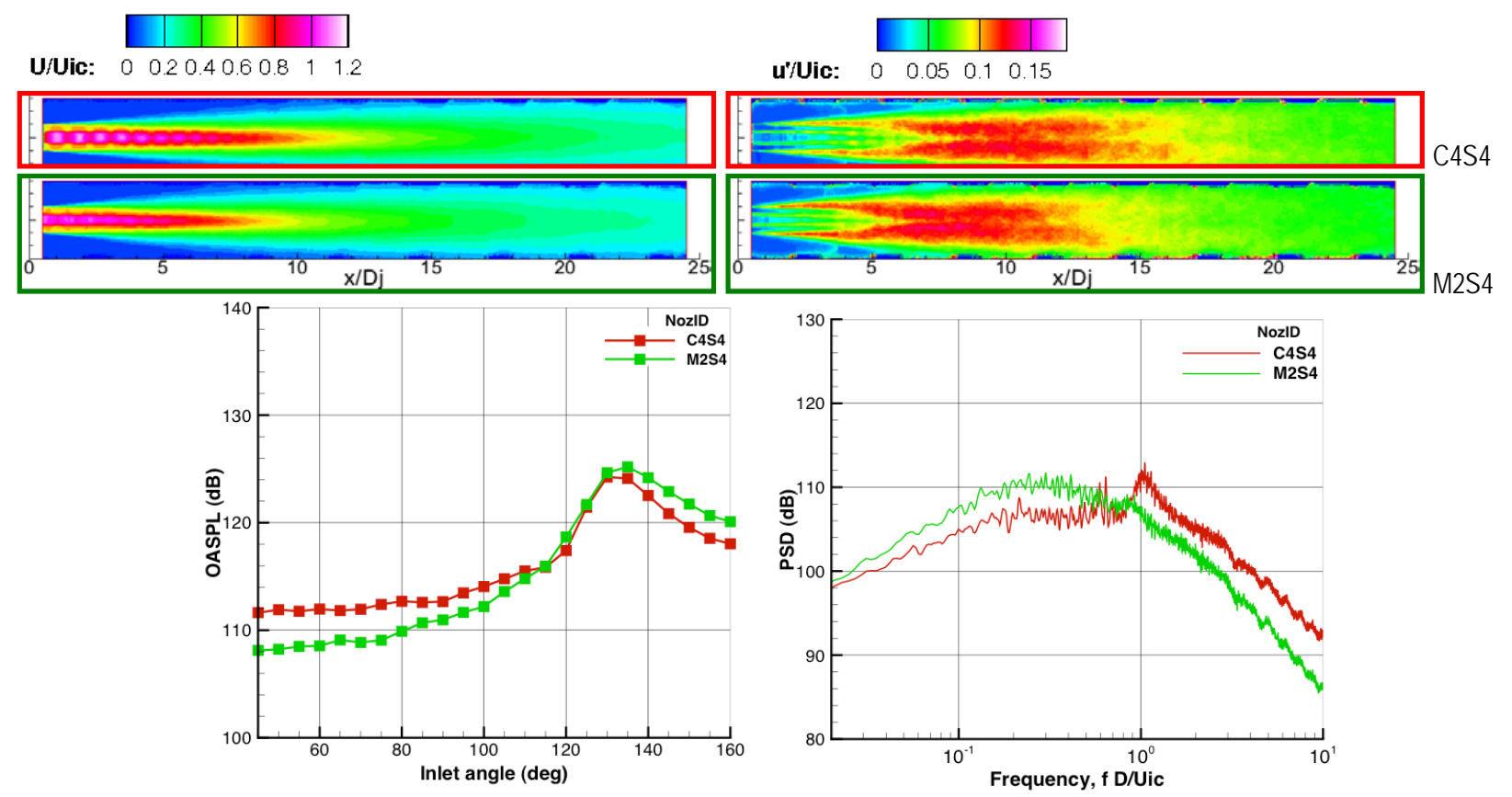

Figure 21.-Splitter area ratio $=3$, convergent C4 versus convergent-divergent M2 nozzles (setpoint 8060; $M=1.19$, $\left.T_{t, c} / T_{\infty}=2.76\right)$.

\section{Splitter Area Ratio $=3.0$}

Moving on to even higher bypass ratios, the bypass sheath thickens a bit more, accentuating the effect seen going from 0.2 to 2.0. So in Figure 21 the potential core of the fully expanded nozzle ends even further upstream than the convergent nozzle, bringing with it the peak turbulence regions. The radial shift in the peak turbulence with increasing axial distance is very pronounced as the two shear layers merge at 
almost the same location as the end of the potential core. Here the convergent nozzle has a much longer potential core than the C-D nozzle, but the peak turbulence levels are very comparable.

In the noise spectrum, the mixing noise of the C-D nozzle is some $3 \mathrm{~dB}$ higher at $90^{\circ}$ to the jet although the two jets have very similar peak noise in the aft angles. The BBSN of the convergent nozzle adds to the jet mixing noise at broadside angles to raise the OASPL above that of the convergentdivergent nozzle. The dominance of the jet mixing noise at the aft angle at this relatively low Mach number causes the OASPL of the convergent-divergent nozzle to be greater at these angles.

\section{Discussion}

In comparisons of the flows from convergent nozzles with splitter area ratio $=0.2$ at different Mach numbers and temperatures, there seems to be a correlation between screech and enhanced turbulence in the initial shear layer (see Figure 15 through Figure 18). This is reasonable since the screech entails amplification of large-scale vortical structures in the shear layer. It is unlikely that Reynolds-averaged simulations will reproduce this effect if it is indeed an effect of the unsteady flow amplification of screech.

Implicit in the discussions of the jet mixing noise, as observed in the spectra at $90^{\circ}$ to the jet, is that this noise is directly correlated with the turbulent velocity. This presumption comes from many theoretical developments, especially related to acoustic analogies that show how the noise is related to the turbulent kinetic energy to the 7/2 power. While this correlation held loosely for most of the cases studied here it clearly doesn't hold for the noise in the aft directions at the highest jet speeds. For example, in Figure 19 the rms velocity contours of the two nozzles were very similar in level and area (hence volume), and the mixing noise component of the spectra at $90^{\circ}$ were comparable. However, the convergent-divergent nozzle was over $10 \mathrm{~dB}$ louder at its peak angle than the convergent nozzle. This demonstrates the fact that just knowing the turbulence levels of the jets will not be adequate to predict the noise at these downstream angles for jets with Mach numbers greater than roughly 1.5.

The choice of core velocity for normalizing the flow and sound data was not arbitrary. While this is clearly a good choice for the mean velocity contours it is not such a clear choice for the turbulence plots. If anything one would expect that the peak levels in the downstream portions of the jet would depend on the local gradient that in turn is dominated by the fully mixed velocity. This was true. Compare the contour plots of rms turbulent velocities in Figure 22 with the same data in Figure 13. The peak turbulence levels in the jets with different splitter area ratios match well when normalized by massweighted velocities (Figure 22), whereas they were distinctly different when normalized by core velocity in Figure 13.

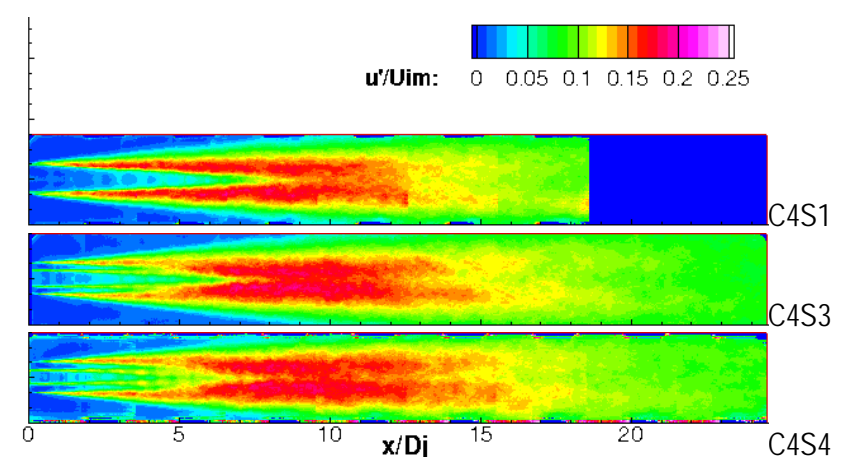

Figure 22.-Turbulent velocity, $u^{\prime} / U_{i m}$, convergent nozzle C4, various splitter area ratios (setpoint $8060 ; M=1.19$, $\left.T_{t, c} / T_{\infty}=2.76\right)$. Note normalization with fully mixed ideally expanded velocities. 
There was no similar good scaling of the acoustic data with velocity. Simple power laws for noise are very dependent on polar angle even at subsonic jet speeds, and become very erratic as convection speeds approach sonic. Toss in the low power scaling of the BBSN noise component and no simple collapse of the acoustic data could be achieved with a single velocity scaling law. Using the core velocity for Strouhal number at least gave a constant factor when comparing jets of the same core velocity.

\section{Summary}

Both acoustic and particle image velocimetry measurements have been made on internally mixed exhaust systems running at Mach numbers between 1 and 1.5. The exhaust systems had different internal area ratios and used both convergent and ideally expanded nozzles. The experiment was designed to hold the Mach number of the flow constant to keep the shock structure of the jet fixed. Changing the temperature of the core then changed the jet velocity and changing the internal splitter area ratio changed the turbulence distribution and the mixed velocity of the fully mixed jet. The flow measurements showed that the common shock structure of the plume was barely affected by the changes in area ratio or velocity ratio for a given Mach number. The noise was more significantly affected. In the analysis of the data turbulence intensities were shown to scale on local mean gradients, as expected, and the jet mixing noise measured broadside to the jet generally scaled with the peak turbulence intensities, again as expected. At the high end of the Mach number range the independence of Mach wave emission noise sources from the

turbulence was also captured. The documented changes in local gradients, and hence turbulence and noise source strength, caused by varying the area ratio of the dual stream flows, will be of use in jet noise modeling and in understanding how to manipulate jet velocity profiles to minimize noise production in future aircraft. The detailed flow data will also be useful in validating Reynolds-Averaged Navier-Stokes prediction methods, and Large Eddy Simulation codes.

\section{References}

1. Bridges, J. “Broadband Shock Noise in Internally-Mixed Dual-Stream Jets,” AIAA paper 2009-3210, (2009).

2. Tanna, H. K. “An Experimental Study of Jet Noise, Part II: Shock Associated Noise.” J. Sound and Vibration, 50(3), pp. 429-444, (1977).

3. Viswanathan, K., Alkislar, M., and Czech, M. "Characteristics of the Shock Noise Component of Jet Noise,” AIAA Paper 2008-2835, (2008).

4. Tam C. K. W. and Burton D. E. "Sound generated by instability waves of supersonic flows. Part 1. Two dimensional mixing layers,” J. Fluid Mech. 138, pp. 249-271, 1984.

5. Shields, F. D. and Bass, H. E. “Atmospheric Absorption of High Frequency Noise and Application to Fractional-Octave Band,” NASA-CR 2760, (1977).

6. Bridges, J. and Wernet, M.P. “Validating LES for Jet Aeroacoustics,” AIAA Paper 2011-0017 (2011).

7. Tam, C.K.W., Chen, P., Seiner, J.M. "Relationship between instability waves and noise of high-speed jets.” AIAA J. 30, pp. 1747-52 (1993). 



\begin{tabular}{|c|c|c|}
\hline \multicolumn{2}{|c|}{ REPORT DOCUMENTATION PAGE } & $\begin{array}{l}\text { Form Approved } \\
\text { OMB No. 0704-0188 }\end{array}$ \\
\hline \multicolumn{3}{|c|}{ 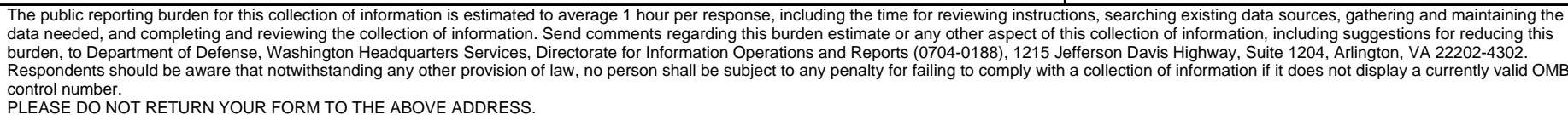 } \\
\hline $\begin{array}{l}\text { 1. REPORT DATE (DD-MM-YYYY) } \\
01-03-2012\end{array}$ & $\begin{array}{l}\text { 2. REPORT TYPE } \\
\text { Technical Memorandum }\end{array}$ & 3. DATES COVERED (From - To) \\
\hline \multirow{3}{*}{\multicolumn{2}{|c|}{$\begin{array}{l}\text { 4. TITLE AND SUBTITLE } \\
\text { PIV Measurements of Supersonic Internally-Mixed Dual-Stream Jets }\end{array}$}} & 5a. CONTRACT NUMBER \\
\hline & & 5b. GRANT NUMBER \\
\hline & & 5c. PROGRAM ELEMENT NUMBER \\
\hline \multirow{3}{*}{\multicolumn{2}{|c|}{$\begin{array}{l}\text { 6. AUTHOR(S) } \\
\text { Bridges, James, E.; Wernet, Mark, P. }\end{array}$}} & 5d. PROJECT NUMBER \\
\hline & & 5e. TASK NUMBER \\
\hline & & $\begin{array}{l}\text { 5f. WORK UNIT NUMBER } \\
\text { WBS 984754.02.07.03.17.08 }\end{array}$ \\
\hline \multicolumn{2}{|c|}{$\begin{array}{l}\text { 7. PERFORMING ORGANIZATION NAME(S) AND ADDRESS(ES) } \\
\text { National Aeronautics and Space Administration } \\
\text { John H. Glenn Research Center at Lewis Field } \\
\text { Cleveland, Ohio 44135-3191 }\end{array}$} & $\begin{array}{l}\text { 8. PERFORMING ORGANIZATION } \\
\text { REPORT NUMBER } \\
\text { E-18005 }\end{array}$ \\
\hline \multirow{2}{*}{\multicolumn{2}{|c|}{$\begin{array}{l}\text { 9. SPONSORING/MONITORING AGENCY NAME(S) AND ADDRESS(ES) } \\
\text { National Aeronautics and Space Administration } \\
\text { Washington, DC 20546-0001 }\end{array}$}} & $\begin{array}{l}\text { 10. SPONSORING/MONITOR'S } \\
\text { ACRONYM(S) } \\
\text { NASA }\end{array}$ \\
\hline & & $\begin{array}{l}\text { 11. SPONSORING/MONITORING } \\
\text { REPORT NUMBER } \\
\text { NASA/TM-2012-217250 }\end{array}$ \\
\hline
\end{tabular}

\section{DISTRIBUTIONIAVAILABILITY STATEMENT}

Unclassified-Unlimited

Subject Categories: 34 and 71

Available electronically at http://www.sti.nasa.gov

This publication is available from the NASA Center for AeroSpace Information, 443-757-5802

\section{SUPPLEMENTARY NOTES}

\section{ABSTRACT}

While externally mixed, or separate flow, nozzle systems are most common in high bypass-ratio aircraft, they are not as attractive for use in lower bypass-ratio systems and on aircraft that will fly supersonically. The noise of such propulsion systems is also dominated by jet noise, making the study and noise reduction of these exhaust systems very important, both for military aircraft and future civilian supersonic aircraft. This paper presents particle image velocimetry of internally mixed nozzle with different area ratios between core and bypass, and nozzles that are ideally expanded and convergent. Such configurations independently control the geometry of the internal mixing layer and of the external shock structure. These allow exploration of the impact of shocks on the turbulent mixing layers, the impact of bypass ratio on broadband shock noise and mixing noise, and the impact of temperature on the turbulent flow field. At the 2009 AIAA/CEAS Aeroacoustics Conference the authors presented data and analysis from a series of tests that looked at the acoustics of supersonic jets from internally mixed nozzles. In that paper the broadband shock and mixing noise components of the jet noise were independently manipulated by holding Mach number constant while varying bypass ratio and jet temperature. Significant portions of that analysis was predicated on assumptions regarding the flow fields of these jets, both shock structure and turbulence. In this paper we add to that analysis by presenting particle image velocimetry measurements of the flow fields of many of those jets. In addition, the turbulent velocity data documented here will be very useful for validation of computational flow codes that are being developed to design advanced nozzles for future aircraft.

15. SUBJECT TERMS

Airport noise; Jet noise; Aeroacoustics; Large eddy simulation; Supersonic aircraft; Particle image velocimetry

\begin{tabular}{|c|c|c|c|c|c|}
\hline \multicolumn{3}{|c|}{ 16. SECURITY CLASSIFICATION OF: } & \multirow{2}{*}{$\begin{array}{l}\text { 17. LIMITATION OF } \\
\text { ABSTRACT } \\
\text { UU }\end{array}$} & \multirow{2}{*}{$\begin{array}{l}\text { 18. NUMBER } \\
\text { OF } \\
\text { PAGES } \\
28\end{array}$} & \multirow{2}{*}{$\begin{array}{l}\text { 19a. NAME OF RESPONSIBLE PERSON } \\
\text { STI Help Desk (email:help@sti.nasa.gov) } \\
\text { 19b. TELEPHONE NUMBER (include area code) } \\
\text { 443-757-5802 }\end{array}$} \\
\hline $\begin{array}{l}\text { a. REPORT } \\
\mathrm{U}\end{array}$ & $\begin{array}{l}\text { b. ABSTRACT } \\
\text { U }\end{array}$ & $\begin{array}{l}\text { c. THIS } \\
\text { PAGE } \\
\text { U }\end{array}$ & & & \\
\hline
\end{tabular}



